\title{
Implementation performance evaluation of hierarchical diagnosis and treatment system in China based on a sustainable perspective
}

\section{Qinde Wu}

Fujian Medical University Union Hospital

Xianyu Xie ( $\nabla$ xiexianyu0221@163.com )

Fujian Medical University Union Hospital https://orcid.org/0000-0002-3294-7990

\section{Research}

Keywords: Hierarchical diagnosis and treatment system, Implementation Performance, China, Sustainability

Posted Date: March 7th, 2022

DOI: https://doi.org/10.21203/rs.3.rs-1410521/v1

License: (c) (i) This work is licensed under a Creative Commons Attribution 4.0 International License. Read Full License 


\title{
Implementation performance evaluation of hierarchical diagnosis and treatment system in China based on a sustainable perspective
}

\author{
Qinde Wu Xianyu Xie* \\ Fujian Medical University Union Hospital, Fuzhou, Fujian, China \\ *Correspondence: Xianyu Xie, Fujian Medical University Union Hospital, Fuzhou, Fujian, China \\ Email address: xiexianyu0221@163.com, Tel:+0086-18805903226 \\ Received: date; Accepted: date; Published: date
}

\begin{abstract}
Hierarchical diagnosis and treatment system is essential for addressing the problem of 'difficult and expensive medical treatment'. But little research has focused on a sustainable perspective when evaluating the hierarchical diagnosis and treatment system performance. Using data from a total of 69 sample data in Fujian Province from 2018 to 2020 as representativeness, we explore the position of the hierarchical diagnosis and treatment policies, clarify the important restrictive factors presently, to better reflect the main contradictions in the Hierarchical Diagnosis and Treatment System in China. We find that the average value of the implementation performance of Hierarchical Diagnosis and Treatment System was $>0.5$, which was at Level III. "Number of new technologies and new projects performed by hospitals and primary health technicians per $100\left(\mathrm{~B}_{3}\right)^{\prime}$, "Number of people per 100 health technicians in the hospitals to the primary medical institutions for guidance $\left(\mathrm{B}_{2}\right)$ ", "Contracted coverage rate of family doctors $\left(F_{3}\right)^{\prime}$ and "Proportion of master's and doctor's degrees of hospital health technicians (A6)" are important factors to promote the performance of Hierarchical Diagnosis and Treatment System at this stage. Our results suggest that policy makers need to smooth the communication and interaction channel of professional disciplines and fully play to the role of medical information technology, pay attention to the construction of family doctors and improve the service level of first diagnosis at the primary level, and improve the medical service capacity of the hospitals through supplement high-quality medical personnel.
\end{abstract}

Keywords: Hierarchical diagnosis and treatment system; Implementation Performance; China; Sustainability 


\section{Introduction}

At present, China is facing an aging population and increasing chronic non-communicable diseases. According to the main data bulletin of the Seventh National Population Census, by 2020, China's population over 60 years old was 264 million, accounting for $18.7 \%$ of the total population.[1] It is expected that by 2025 the population over 60 will exceed 300 million and China will become a super-elderly country.[2] According to the data of the Report on Nutrition and Chronic Diseases of Chinese Residents (2020), the number of deaths from chronic diseases in China accounted for $88.5 \%$ of the total deaths in 2019.[3] The Blue Book on Health Management: China Health Management and Health Industry Development Report (2020) points out that about 300 million people suffer from chronic diseases in China, of which $50 \%$ are under 65 . Aging and chronic diseases not only bring great economic burden and medical resource consumption to the country, society and the people themselves, but also affect the overall and long-term development, social stability and economic sustainable development of the country.[4][5][6][7] At the same time, there are some problems in China, such as unreasonable layout structure of health resources and fragmentation of medical and health service system, which make high-quality medical resources excessively concentrated in large public hospitals in cities. However, the service ability of primary medical and health institutions is insufficient, resulting in a large number of patients entering large hospitals, resulting in the problem of 'difficult and expensive medical treatment', resulting in the continuous and holistic service of national diseases, the medical cost is extremely consumed, and the health equity is reduced.

In order to solve these problems, China puts forward the hierarchical diagnosis and treatment system, which refers to the classification according to the severity of the disease and the difficulty of treatment. Different levels of medical institutions bear the treatment of different diseases, and gradually realize the medical process from general practice to specialization, and realize' primary diagnosis, two-way referral, acute and chronic treatment, upper and lower linkage'. In March 2009, the State Council of the Central Committee of the Communist Party of China issued the Opinions on Deepening the Reform of the Medical and Health System (No. 6 of the Central Committee of the Communist Party of China), proposing a new round of medical reform, and taking the hierarchical diagnosis and treatment system as the core system. In September 2015, the General Office of the State Council issued 'Guidance on Promoting the Construction of 
Hierarchical Diagnosis and Treatment System' (No. 70 of the State Administration), which further strengthened the concept of hierarchical diagnosis and treatment. The 18th National Congress of the Communist Party of China has upgraded 'Healthy China' to a national strategy, putting health in the position of priority development. Hierarchical diagnosis and treatment system is the most important measure to realize the strategy of Healthy China. However, the hierarchical diagnosis and treatment system has promoted ten years, and it is still difficult to implement. It has not formed the order of hierarchical diagnosis and treatment, and the problem of 'difficult to see a doctor' is still prominent. The outbreak of new coronavirus pneumonia in 2020 has once again exposed the severity and urgency of the above problems, and the hierarchical diagnosis and treatment system has once again become the focus and focus of social attention. Therefore, what is the implementation performance of the hierarchical diagnosis and treatment system at the present stage, what level is its performance level, what is its core problem, and what core problem can be solved to further promote the continuous operation of the hierarchical diagnosis and treatment system, which are the main issues of concern to us.

Fujian Province, like most parts of the country, is faced with the problem of insufficient motivation for the implementation of the hierarchical diagnosis and treatment system. As one of the first pilot provinces of comprehensive medical reform, Fujian Province takes the lead in implementing the hierarchical diagnosis and treatment system, which has certain representativeness. Studying the existing problems can play a role in peeping at the hierarchical diagnosis and treatment system in China. Therefore, this paper will take Fujian as an example to study the implementation performance of the hierarchical diagnosis and treatment system at the present stage, measure its level, find out the existing problems, and put forward corresponding countermeasures to provide basic support for the realization of the strategic goal of healthy China.

\section{Literature Review}

The evaluation of Chinese scholars on the hierarchical diagnosis and treatment system mainly focuses on the implementation status of the hierarchical diagnosis and treatment in medical institutions or the comparison of the effects before and after the implementation of the policies. For the implementation status of the hierarchical diagnosis and treatment in medical institutions[8][9], the policy effects of the hierarchical diagnosis and treatment on the graded allocation of health resources[10][11], medical services[12][13], two-way referral[14], income of medical 
and health institutions[15], medical expenses of patients[16], operation of NCMS medical insurance fund[17] and multi-point practice of doctors[18] were mainly analyzed herein. The comparison of the effects before and after the implementation of the hierarchical diagnosis and treatment was evaluated, mainly using stakeholder analysis method and "Result Chain" Model to compare and analyze the health resource investment, telemedicine, first diagnosis at the basic level, standardized diagnosis and management rate of the patients with chronic diseases, cognition and satisfaction of the patients before and after the implementation of different medical consortia and the hierarchical diagnosis and treatment modes[19][20][21][22].

The performance of the hierarchical diagnosis and treatment from the whole health system was evaluated generally by international academic circles. For example, the health system performance evaluation framework of WHO, the health service performance evaluation of the United States, the key indicator system of UK, the national evaluation framework and the international organization of OECD were used for health system performance evaluation framework of standardization. WHO has designed a framework for the evaluation and supervision of current medical and health system reform in China, including four progressive stages: input and process output result impact. The input and process indicators include governance, financing, infrastructure, health manpower, supply chain and information, and the output indicators include security efficiency, intervention measures, intervention quality and service willingness. The outcome indicators include intervention coverage, disease risk, behavior and risk factors. The impact indicators include improving health outcomes and fairness, social and financial risk protection, etc.[23][24][25][26][27][28][29]

Although a variety of fixed health system performance evaluation frameworks have been formed at abroad, they tend to emphasize the measurement of financial indicators and medical service quality, which are unapplicable to the connotation, characteristics and construction objectives of the hierarchical diagnosis and treatment in China. As Musgrove P (2006)[30] believes that, it is unreasonable to apply the same set of evaluation indicators to all countries due to the different national conditions and historical development stages of various countries. Thus, all localities shall adjust measures to local conditions and establish an evaluation indicator system in line with their own national conditions. For the performance evaluation of the hierarchical diagnosis and treatment, domestic scholars mostly start with simple descriptive analysis, or evaluate according to the current situation of the implementation of the hierarchical 
diagnosis and treatment, cannot find the key direction of the development of the system in the future, lack of policy evaluation from a sustainable perspective, and lack of positioning for the implementation effect of the hierarchical diagnosis and treatment policies. Thus, the grey correlation degree was used herein on combination of the Growth Management Model to measure the policy performance based on the construction of the hierarchical diagnosis and treatment performance evaluation system, and the obstacle degree and BP_-DEMATAL algorithm were further used for clarifying the important restrictive factors of the Hierarchical Diagnosis and Treatment System presently, to better reflect the main contradictions existing in the Hierarchical Diagnosis and Treatment System in China, provide reference and basis for government agencies to formulate targeted policies, and then promote the sustainable development of the Hierarchical Diagnosis and Treatment System at this stage.

\section{Materials and Methods}

\subsection{Construction of the evaluation indicator of hierarchical diagnosis and treatment} performance

\subsubsection{Construction of the evaluation Indicator}

The selection of evaluation indicators is the key to the establishment of evaluation system. Based on the research of the evaluation indicator system and related scholars constructed by the Health Development Research Center of China Health Commission in the evaluation of hierarchical diagnosis and treatment and the construction of medical consortium, this paper established the performance evaluation indicator system of hierarchical diagnosis and treatment from seven aspects, namely, the service capacity construction of medical institutions, communication and interaction, incentive compatibility, division of labor and cooperation, triage effect, health benefit and medical cost control. A total of 27 third-level indicators were formed as an important reference and evaluation basis for the performance evaluation of hierarchical diagnosis and treatment. Among them, there were 7 indicators of service capacity building, 3 indicators of communication and interaction, 4 indicators of incentive compatibility, 2 indicators of division of labor and cooperation, 5 indicators of triage effect, 3 indicators of health benefits, and 3 indicators of medical cost control.

\section{(i) Hierarchical diagnosis and treatment resource allocation}

The construction of the service capacity of medical institutions includes the infrastructure construction of primary medical and health institutions and the 
high-quality development of public hospitals. The construction of primary medical and health institutions infrastructures includes the construction of personnel team and investment of financial investment and material resources. The proportion of practicing (assistant) doctors sent by hospitals to primary medical and health institutions reflects the importance attached by hospitals to supporting primary institutions, and it is a measure to improve the capacity of primary medical services.[31] The number of doctors in primary medical and health institutions is an important symbol of the rational distribution of medical and health talents in urban and rural areas and regions.[32] The special financial funds for the construction of the hierarchical diagnosis and treatment represent the continuous attention and investment of government in the hierarchical diagnosis and treatment.[33] Hierarchical diagnosis and treatment requires a certain number of advanced medical equipment and facilities in primary medical institutions. The core of high-quality development of public hospitals lies in personnel. The best indicators are the proportion of master's and doctor's degrees of hospital health technicians and scientific study funds per 100 health technicians.[34] Thus, seven indicators are selected for measurement, such as the proportion of (assistant) doctors assigned by hospitals to the primary medical and health institutions(A1), the number of (assistant) doctors per 1,000 permanent residents in primary medical and health institutions $\left(\mathrm{A}_{2}\right)$, the number of equipment above 10,000 yuan per 1,000 permanent residents in primary medical and health institutions $\left(A_{3}\right)$, the number of beds per 1,000 permanent residents in primary medical and health institutions $\left(\mathrm{A}_{4}\right)$, the financial special funds for the hierarchical diagnosis and treatment construction per 1,000 permanent residents $\left(\mathrm{A}_{5}\right)$, the proportion of master's and doctor's degrees of hospital health technicians $\left(\mathrm{A}_{6}\right)$ and the scientific study funds per 100 health technicians in the hospitals $\left(\mathrm{A}_{7}\right)$.

\section{(ii) Communication and interaction}

Hospitals improve the service capacity of primary medical institutions by means of resource sinking and extensive coverage. The study of primary health technicians in hospitals is necessary for retraining and upgrading, which can be measured by the number of people per 100 health technicians at the primary institutions studying in hospitals. The number of people per 100 health technicians in the hospitals go to the primary medical institutions for guidance can explain the process of continuous guidance and support of public hospitals to primary medical institutions.[35] The more new technologies and new projects performed by the hospitals and the primary medical 
institutions cooperation, the more it can promote the the hierarchical diagnosis and treatment continuously.[36] Thus, three indicators are selected for measurement: the number of people per 100 health technicians at the primary institutions studying in hospitals $\left(B_{1}\right)$, the number of people per 100 health technicians in the hospitals to the primary medical institutions for guidance $\left(\mathrm{B}_{2}\right)$, and the number of new technologies and new projects performed by hospitals and primary health technicians per $100\left(\mathrm{~B}_{3}\right)$.

\section{(iii) Incentive compatibility}

The formulation and implementation of the Hierarchical Diagnosis and Treatment System shall rely on the establishment of the government financial policies. The support of the governmental financial funds can improve the enthusiasm of medical institutions to participate in the hierarchical diagnosis and treatment. The medical insurance incentive system is very important for the development of the hierarchical diagnosis and treatment. Medical insurance is the main payer of medical expenses in China and a sharp weapon to regulate the medical treatment and medical treatment behavior of both doctors and patients.[37] The premise of the realization of the hierarchical diagnosis and treatment is the construction of the hierarchical diagnosis and treatment management system, including the construction of work quality assessment system and personnel salary system in medical institutions. Thus, the construction of the hierarchical diagnosis and treatment management system is measured by four indicators: government financial investment policy $\left(C_{1}\right)$, medical insurance incentive system $\left(C_{2}\right)$, work quality assessment system of medical institutions $\left(\mathrm{C}_{3}\right)$ and personnel salary system of medical institutions $\left(\mathrm{C}_{4}\right)$.

\section{(iv) Division of labor and cooperation}

Division of labors and cooperation includes the determination of division of labors and the establishment of cooperative relations. The premise is the integration of medical resources. The construction of resource integration system is the premise to clarify how to integrate medical resources, optimize the allocation of medical resources and realize the sinking of high-quality medical resources.[38] The premise of division of labors and cooperation is the construction of resource division system, and a better resource division system shall be formulated to support the institutional environment. Thus, the resource integration system $\left(D_{1}\right)$ and the resource division system $\left(D_{2}\right)$ are selected for measurement.

(v) Triage effects 
The most intuitive effect change of triage effects is to improve the medical service capacity of primary medical and health institutions. The proportion of primary outpatient and emergency visits is the most intuitive indicator[39]. According to the ideal state of the hierarchical diagnosis and treatment, the utilization rate of inpatient beds in primary shall be at a high level, which is an intuitive embodiment of whether the hierarchical diagnosis and treatment meets the standard.[40] The hierarchical diagnosis and treatment requires the hospitals to be responsible for the treatment of acute and critical diseases. The most intuitive indicators are the proportion of level III and IV surgery in hospital and the coincidence rate of main diagnosis in admission and discharge in hospital, which is also the concentrated embodiment of the comprehensive strength of the hospitals.[41] Up and down referrals can provide the patients with accessible and continuous medical services. The proportion of up and down referrals is an intuitive indicator of whether the hierarchical diagnosis and treatment is really formed.[42] Thus, five indicators were selected for measurement, including the proportion of outpatient and emergency visits in primary medical and health institutions $\left(E_{1}\right)$, the utilization rate of inpatient beds in primary medical and health institutions $\left(E_{2}\right)$, the proportion of level III and IV surgery in hospital $\left(\mathrm{E}_{3}\right)$, the Coincidence rate of main diagnosis in admission and discharge in hospital $\left(\mathrm{E}_{4}\right)$, and the proportion of up-down referrals $\left(\mathrm{E}_{5}\right)$.

\section{(vi) Health Benefits}

The goal of the hierarchical diagnosis and treatment is to improve the health level.[43] The infant mortality in a region is an important indicator to measure the health level of a region. The chronic diseases account for the highest proportion of all kinds of diseases. The management rate of chronic diseases can affect the health level of the region directly.[44] The contracted coverage rate of family doctors is the main evaluation indicator to ensure the convenience of medical treatment, improve the regional health level and promote the development of hierarchical diagnosis and treatment.[45] Thus, infant mortality $\left(\mathrm{F}_{1}\right)$, chronic disease management rate $\left(\mathrm{F}_{2}\right)$ and contracted coverage rate of family doctors $\left(\mathrm{F}_{3}\right)$ are selected for measurement.

\section{(vii) Medical Cost Control}

The proportion of hospitalization medical expenses is very high compared with outpatient and emergency department for the patients. Thus, the change rate of self-payment burden per hospitalization is selected as a representative indicator to 
measure medical costs and medical burden.[46] The medical insurance fund balance rate is the key indicator to measure the cost control and internal management of medical institutions.[47] The balance rate of annual revenue and expenditure of medical institutions can bring a virtuous circle for the sustainable development of medical institutions and the improvement of medical service level to make the Hierarchical Diagnosis and Treatment System sustainable, which is a basic condition for the realization of hierarchical diagnosis and treatment.[48] Thus, three indicators were selected for measurement: the change rate of self-payment burden per hospitalization $\left(\mathrm{G}_{1}\right)$, the balance rate of medical insurance fund $\left(\mathrm{G}_{2}\right)$ and the annual balance rate of revenue and expenditure $\left(\mathrm{G}_{3}\right)$.

Based on the above analysis, the performance evaluation indicator system of hierarchical diagnosis and treatment system is established, as shown in Table 1.

Table 1 Performance Evaluation Indicator System of Hierarchical Diagnosis and Treatment System

\begin{tabular}{|c|c|}
\hline Level 2 Indicator & Level 3 Indicators \\
\hline \multirow{7}{*}{$\begin{array}{l}\text { Hierarchical diagnosis } \\
\text { and treatment resource } \\
\text { allocation } \mathrm{A}\end{array}$} & $\begin{array}{l}\text { Proportion of (assistant) doctors assigned by hospitals to the primary } \\
\text { medical and health institutions(A1) }\end{array}$ \\
\hline & $\begin{array}{l}\text { Number of (assistant) doctors per } 1,000 \text { permanent residents in primary } \\
\text { medical and health institutions }\left(\mathrm{A}_{2}\right)\end{array}$ \\
\hline & $\begin{array}{l}\text { Number of equipment above } 10,000 \text { yuan per } 1,000 \text { permanent residents } \\
\text { in primary medical and health institutions }\left(\mathrm{A}_{3}\right)\end{array}$ \\
\hline & $\begin{array}{l}\text { Number of beds per } 1,000 \text { permanent residents in primary medical and } \\
\text { health institutions }\left(\mathrm{A}_{4}\right)\end{array}$ \\
\hline & $\begin{array}{l}\text { Financial special funds for the hierarchical diagnosis and treatment } \\
\text { construction per } 1,000 \text { permanent residents }\left(A_{5}\right)\end{array}$ \\
\hline & $\begin{array}{l}\text { Proportion of master's and doctor's degrees of hospital health } \\
\text { technicians }\left(\mathrm{A}_{6}\right)\end{array}$ \\
\hline & Scientific study funds per 100 health technicians in the hospitals $\left(\mathrm{A}_{7}\right)$ \\
\hline \multirow{3}{*}{$\begin{array}{l}\text { Communication } \\
\text { interaction } \mathrm{B}\end{array}$} & $\begin{array}{l}\text { Number of people per } 100 \text { health technicians at the primary institutions } \\
\text { studying in hospitals }\left(\mathrm{B}_{1}\right)\end{array}$ \\
\hline & $\begin{array}{l}\text { Number of people per } 100 \text { health technicians in the hospitals to the } \\
\text { primary medical institutions for guidance }\left(B_{2}\right)\end{array}$ \\
\hline & $\begin{array}{l}\text { Number of new technologies and new projects performed by hospitals } \\
\text { and primary health technicians per } 100\left(\mathrm{~B}_{3}\right)\end{array}$ \\
\hline \multirow{4}{*}{ Incentive compatibility $\mathrm{C}$} & Government financial investment policy $\left(\mathrm{C}_{1}\right)$ \\
\hline & Medical insurance incentive system $\left(\mathrm{C}_{2}\right)$ \\
\hline & Work quality assessment system of medical institutions $\left(\mathrm{C}_{3}\right)$ \\
\hline & Personnel salary system of medical institutions $\left(\mathrm{C}_{4}\right)$ \\
\hline \multirow{2}{*}{$\begin{array}{l}\text { Division of labor and } \\
\text { cooperation D }\end{array}$} & Resource integration system $\left(\mathrm{D}_{1}\right)$ \\
\hline & Resource division system $\left(\mathrm{D}_{2}\right)$ \\
\hline Triage effect E & Proportion of outpatient and emergency visits in primary medical and \\
\hline
\end{tabular}




\begin{tabular}{|c|c|}
\hline & \multirow{2}{*}{$\begin{array}{l}\text { health institutions }\left(\mathrm{E}_{1}\right) \\
\begin{array}{l}\text { Utilization rate of inpatient beds in primary medical and health } \\
\text { institutions }\left(\mathrm{E}_{2}\right)\end{array}\end{array}$} \\
\hline & \\
\hline & Proportion of level III and IV surgery in hospital $\left(\mathrm{E}_{3}\right)$ \\
\hline & $\begin{array}{l}\text { Coincidence rate of main diagnosis in admission and discharge in } \\
\text { hospital }\left(E_{4}\right)\end{array}$ \\
\hline & Proportion of up-down referrals $\left(E_{5}\right)$ \\
\hline \multirow{3}{*}{ Health benefits $F$} & Infant mortality $\left(\mathrm{F}_{1}\right)$ \\
\hline & Chronic disease management rate $\left(\mathrm{F}_{2}\right)$ \\
\hline & Contracted coverage rate of family doctors $\left(\mathrm{F}_{3}\right)$ \\
\hline \multirow{3}{*}{ Medical cost control G } & Change rate of self-payment burden per hospitalization $\left(\mathrm{G}_{1}\right)$ \\
\hline & Balance rate of medical insurance fund $\left(\mathrm{G}_{2}\right)$ \\
\hline & Annual balance rate of revenue and expenditure $\left(\mathrm{G}_{3}\right)$ \\
\hline
\end{tabular}

In order to verify the stability of the performance evaluation indicator system of hierarchical diagnosis and treatment, we use CRITIC method and entropy weight method to calculate the weight of sample data, and calculate the evaluation scores of each sample. The rank of the total scores of the two methods is tested by symbolic rank test. The results show that the $\mathrm{p}$ value is 0.625 . There is no sufficient reason to reject the original hypothesis. Therefore, it can be considered that the weight values calculated by the two methods are not significantly different, so that the evaluation indicator system is objective and stable.

\section{Methods}

\subsection{Data}

The sample data selected in this paper are from a total of 69 sample data of 23 integrated medical service institutions in Fujian Province from 2018 to 2020.

\subsection{Research methods and models}

\subsubsection{Grey correlation method}

The advantage of grey correlation method is based on the theory of dealing with complex systems, and it has more practical value under the conditions of less data and conditions that do not meet the statistical requirements. Hierarchical diagnosis and treatment system is a very complex system. In order to achieve the comprehensiveness and rationality of evaluation, the evaluation indicator system must have quantitative and qualitative indicators, so the grey system theory shows its applicability. Grey correlation analysis is a method to measure the degree of correlation between factors according to the similarity or difference of the development trend between factors. The principal 
component analysis and factor analysis in mathematical statistics can also be used to evaluate complex systems, but the mathematical statistics method has its shortcomings. For example, a large number of data are required, and the sample is required to obey a typical probability distribution. The China' s medical data grey is large, the evaluation effect of mathematical statistics is not ideal. At the same time, the calculation results of grey correlation degree can be divided into intervals (See Table 2). [49] Therefore, this paper decided to use the grey correlation method for evaluation, and combined with the CRITIC method to determine the grey correlation degree and average correlation degree of each sample, so as to locate the level of the performance implementation results of the hierarchical diagnosis and treatment system.

Table 2 The division interval of policy effect values based on grey correlation degree

\begin{tabular}{cccccc}
\hline Level & 1 & 2 & 3 & 4 & 5 \\
\hline Value of Grey & & & & & \\
Correlation Degree & $(0,0.3)$ & {$[0.3,05)$} & {$[0.5,0.7)$} & {$[0.7,0.9)$} & {$[0.9,1]$} \\
Policy effect & & & & & \\
& poor & relatively & good & excellent \\
\hline
\end{tabular}

On the basis of considering the weight of each indicator, the grey correlation analysis method is used to evaluate the overall performance of the hierarchical diagnosis and treatment system of 23 evaluation objects, and the effect of policy implementation is measured. The specific steps are as follows:

(i) Determination of Reference Sequence and Comparison Sequence

Set the reference sequence:

$$
Z=\left(z_{1}, z_{2}, \cdots, z_{p}\right)
$$

In the formula, $z_{j}=\max \left(y_{1 j}, y_{2 j}, \cdots, y_{n j}\right), \quad j=1,2, \cdots, p$

\section{(ii)Dimensionless processing}

The range transformation method is used to process the data, so that the positive and negative indicators are converted into positive indicators. The value is between $0-1$, the optimal value is 1 , and the worst value is 0 .

For positive indicators:

$$
y_{i j}=\frac{x_{i j}-\min _{i}\left(x_{i j}\right)}{\max _{i}\left(x_{i j}\right)-\min _{i}\left(x_{i j}\right)},
$$

For reverse indicators: 


$$
y_{i j}=\frac{\max _{i}\left(x_{i j}\right)-x_{i j}}{\max _{i}\left(x_{i j}\right)-\min _{i}\left(x_{i j}\right)},
$$

In the formula, $x_{i j}$ represents the value of the $j^{\text {th }}$ indicator of the $i^{\text {th }}$ sample. $y_{i j}$ represents the value after dimensionless treatment, $i=1, \cdots, n, \mathrm{j}=1, \cdots, p$.

(iii)The calculation of correlation coefficient

Calculation of correlation coefficient $\xi$ between the $j^{\text {th }}$ comparison sequence and the reference sequence by grey correlation coefficient formula:

$$
\xi_{i}\left(Y_{j}, Z\right)=\frac{\min _{i} \min _{j}\left|y_{i j}-z_{j}\right|+\rho \max _{i} \max _{j}\left|y_{i j}-z_{j}\right|}{\left|y_{i j}-z_{j}\right|+\rho \max _{i} \max _{j}\left|y_{i j}-z_{j}\right|} .
$$

In the formula, $\rho$ is a resolution coefficient designed to increase the difference between the correlation coefficients, usually 0.5 .

\section{(iv)The calculation of association}

Since the correlation coefficient can only reflect the correlation degree between data. In order to effectively reflect the overall correlation degree between the comparison sequence and the reference sequence, it is necessary to further calculate the correlation degree based on the index weight calculated by CRITIC method.

$$
R_{i}=\sum_{j=1}^{p} w_{j} \xi_{i}\left(Y_{j}, Z\right) \text {. }
$$

The average correlation of all samples in a given year is:

$$
R=\frac{1}{n} \sum_{i=1}^{n} R_{i}
$$

\subsubsection{Policy Implementation Performance Positioning Model based on Growth Management Model}

The Growth Management Model (GMM) was proposed by IAB (Industry Advisory Committee) in 2014. It is a theoretical framework, aiming at improving organizational management efficiency and overall organizational output from a sustainable perspective, as shown in the following Fig. 1. It has been widely used in the field of organizational diagnosis and can effectively reflect the level of policy implementation performance or implementation effect as a model based on sustainable perspective.[50] Therefore, this paper aims to introduce the Growth Management Model into the field of performance 
evaluation of the implementation of the Hierarchical Diagnosis and Treatment System.

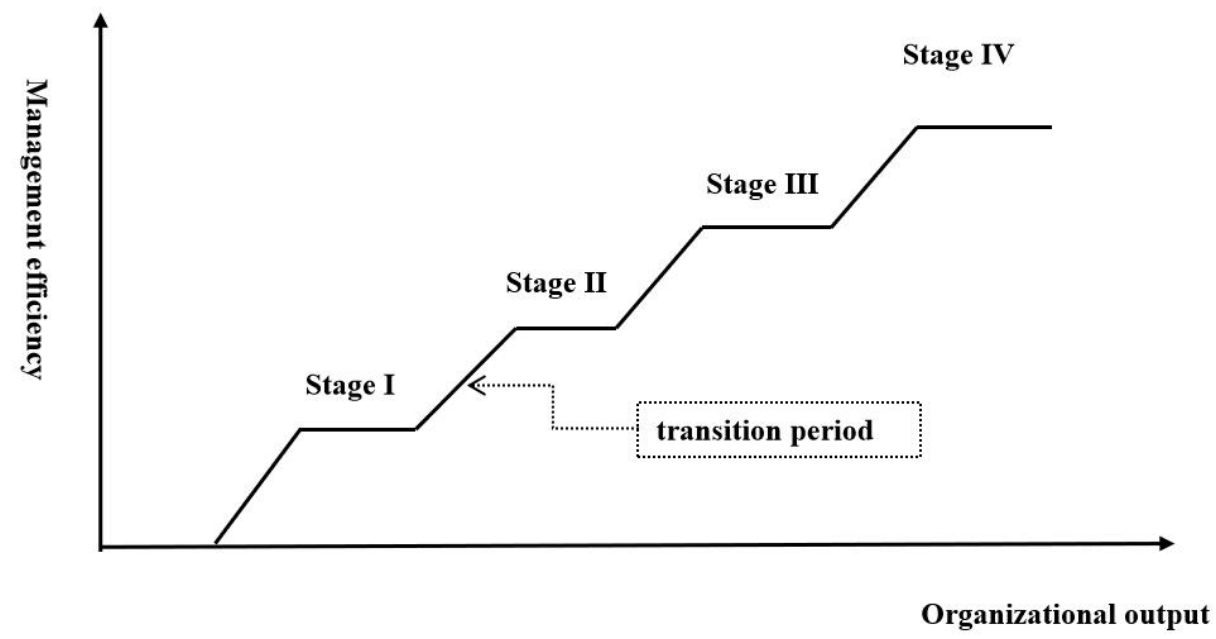

Fig. 1 Growth Management Model

As it can be seen from Fig. 1, the Growth Management Model is an important application tool of sustainable development in the field of organizational diagnosis. It is essentially a function of organizational output on internal management efficiency, and the relationship between them can be reflected by a series of line segments in the Fig.1 effectively. In Fig.1, the horizontal stage (such as Stage I) indicates that the internal management efficiency is in a stable stage, and the transition period indicates that certain measures need to be taken to improve the management efficiency, to achieve higher-level organizational output. Considering the applicability of the Model in different industries, such as agriculture and manufacturing, its application scope can be further extended to the field of the hierarchical diagnosis and treatment. Lessons were drawn in this paper from the sustainable development idea of the Growth Management Model based on this, and the Model was introduced into the evaluation of the implementation performance of the hierarchical diagnosis and treatment. The grey correlation degree and the Growth Management Model were integrated in this paper, and the Hierarchical Diagnosis and Treatment Management Model was constructed based on the perspective of sustainable development. The Model aims to locate the stage of the performance implementation of the Hierarchical Diagnosis and Treatment System, as shown in Fig. 2. 


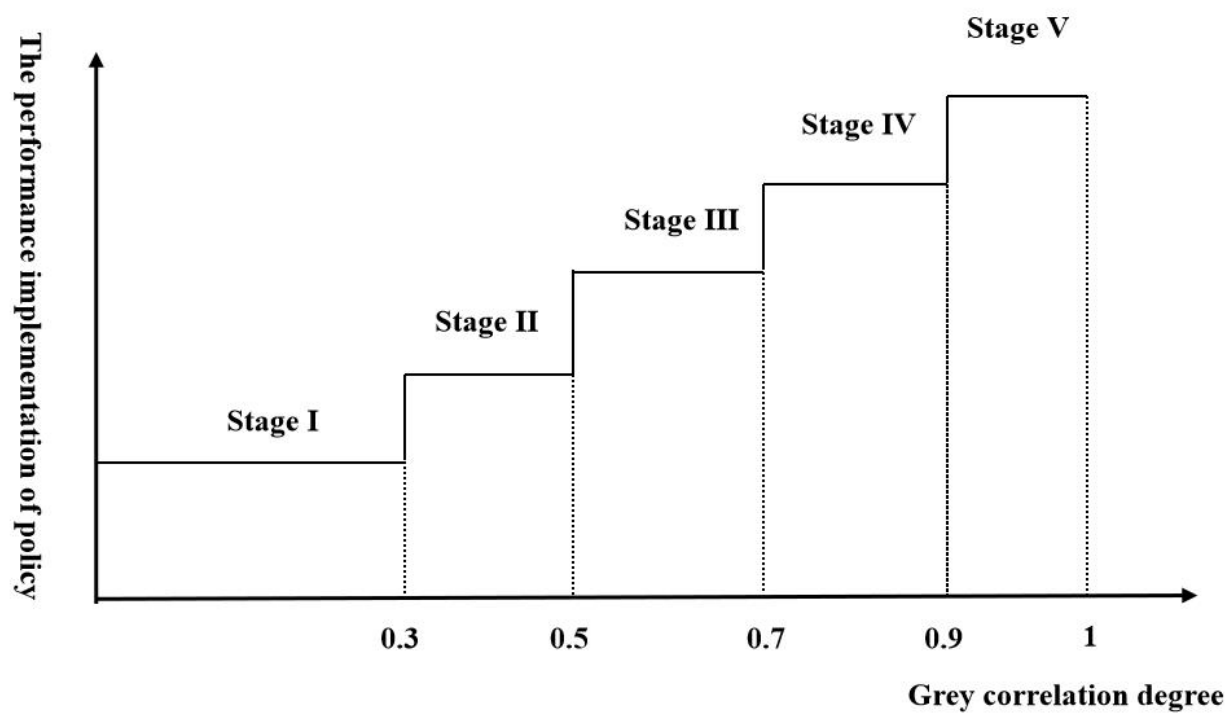

Fig. 2 Performance Growth Management Model of Hierarchical Diagnosis and Treatment System

As it can be seen from Fig. 2, the performance implementation results of the Hierarchical Diagnosis and Treatment System in this Model are divided into five levels on combination of the grey correlation value division interval proposed above. Combined with the value determination interval mentioned above, it indicates that the implementation result of the policy is at a poor level at this time when the value of correlation degree is $<0.3$; it means that the implementation effect of the policy has reached an excellent level when the correlation value is $>0.9$; it means that the implementation effect of the policy still has great room for improvement when the correlation coefficient is $<0.9$. We can locate the level of the implementation effect of the hierarchical diagnosis and treatment policy according to the correlation degree calculated from the sample data based on this. The Model provides a theoretical tool for the positioning of the implementation effect of the hierarchical diagnosis and treatment policy. We can locate and measure the level of the implementation effect of the hierarchical diagnosis and treatment policy through this framework.

\subsubsection{Obstacle Model}

We shall find out the main problems based on the evaluation and location of the implementation performance of the Hierarchical Diagnosis and Treatment System. It is difficult for us to find the existing problems due to the uneven distribution and uneven allocation of medical resources across the country. Thus, we shall use a method to find the core problems, to solve the problem in a targeted manner, which is conducive to the 
rapid and effective continuous operation of the Hierarchical Diagnosis and Treatment System. The Obstacle Model will be used in this section to analyze the obstacle ranking of various indicators, explore the core indicators affecting the Hierarchical Diagnosis and Treatment System, perform targeted analysis around these indicators, find out their existing problems and reasons, and then provide more accurate countermeasures and suggestions for improving the operation of the Hierarchical Diagnosis and Treatment System.

The diagnosis of obstacle factors considers the indicator deviation degree and factor contribution degree comprehensively. The indicator deviation degree refers to the deviation degree from the ideal value, and the factor contribution degree refers to the consideration of weight. Thus, the analysis of obstacle factors pays attention to efficiency, which can fundamentally find out which aspect and which indicator is the weak link in Fujian Province as a whole. The calculation steps are as follows:

$$
\begin{gathered}
O_{j}=\frac{\sum_{i=1}^{m} w_{j} P_{i j}}{\sum_{j=1}^{p} \sum_{i=1}^{m} w_{j} P_{i j}}, \\
P_{i j}=\left|y_{i j}-D_{j}\right|, \\
Q_{d}=\sum_{j=1}^{d_{j}} O_{j},
\end{gathered}
$$

Where, $w_{j}$ refers to the weight of each Level 3 indicator obtained by CRITIC, $y_{i j}$ is the standardized value of each Level 3 indicator, $P_{i j}$ is the absolute value of the difference between each $y_{i j}$ and the positive ideal value, $D_{j}$ is the ideal value of each Level 2 indicator ( here, according to the dimensionless processing, they are all 1 ), $O_{j}$ is the obstacle degree of the $\mathrm{j}^{\text {th }}$ Level 3 indicator (the greater the value, the greater the obstacle effect), $Q_{d}$ represents the obstacle degree of each Level 2 indicator, $d_{j}$ indicates the number of level 3 indicators contained in each level 2 indicator. Similarly, the obstacle degree of level 1 indicator is equal to the sum of the obstacle degrees of level 2 indicators.[51]

\subsubsection{BP-DEMATAL}

The main obstacle factors of the Hierarchical Diagnosis and Treatment System 
have been analyzed through the Obstacle Model in the previous section. How do the 27 indicators interact in the operation process of the hierarchical diagnosis and treatment? Based on the previous section, we continue to distinguish the causal relationship between the indicators in the operation process of the hierarchical diagnosis and treatment, and explore the most important indicators affecting the operation of the Hierarchical Diagnosis and Treatment System among the obstacle indicators, which is conducive to more accurately analyze the main contradictions in the operation process of the Hierarchical Diagnosis and Treatment System, so as to put forward more targeted policy suggestions. This section will deeply analyze the interaction of these Level 3 indicators based on the actual data of 23 integrated medical service institutions.

It is necessary to adopt appropriate methods to explore its potential correlation and law due to the complex relationship between the evaluation indicators of the operation mechanism of the Hierarchical Diagnosis and Treatment System. DEMATEL method is suitable to distinguish the influencing factors of complex problems and show the causal relationship of influencing factors. BP neural network is suitable for describing complex nonlinear problems. BP neural network is introduced into the direct relationship matrix of DEMATEL method to produce the direct relationship matrix between different influencing factors, which is helpful to solve the complex problems between data. Thus, BP-DEMATEL Model is selected and constructed through MATLAB software programming to mine the objective and reliable change characteristics and laws of the operation mechanism of the Hierarchical Diagnosis and Treatment System.

\section{(i) Construction of BP Neural Network Model}

The 23 integrated medical service institutions were taken as the study object, 27 indicators of the performance evaluation of the Hierarchical Diagnosis and Treatment System, 69 observation samples were taken as the input matrix, and comprehensive evaluation score from CRITIC method were taken as the output matrix. The number of hidden layer nodes was taken as 4, 6, 8, 12, 16 and 20, respectively for 10 BP network tests. The mean value of the relative errors is the smallest when 8 nodes were selected in the hidden layer on combination of the mean value of the relative errors of 69 observation samples. Thus, the number of hidden layer nodes of neural network in this paper was taken as 8 . 


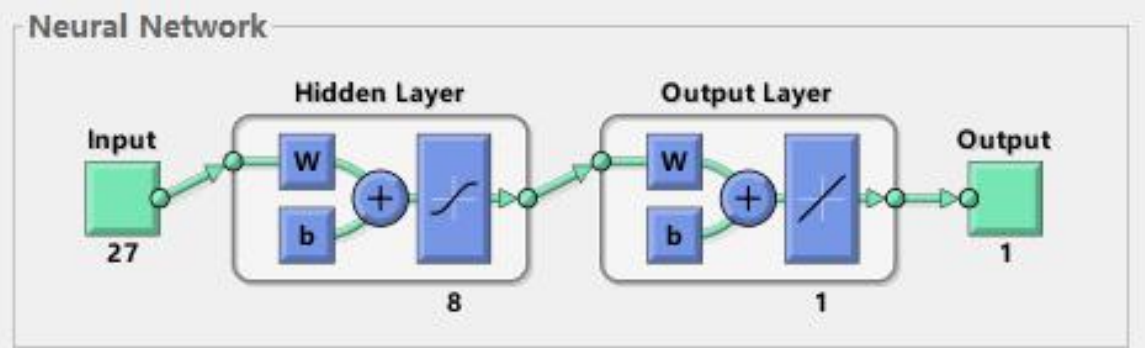

Fig. 3 Construction diagram of BP Neural Network Model

The neuron input matrix is: $X=\left(x_{i j}\right)_{27 \times 69}$, the number of hidden layer neurons is 8 , and the output layer matrix is $Y=\left(y_{i j}\right)_{1 \times 69}$.

\section{(ii) Train BP neural network to get the weight matrix}

The BP network had been constructed repeatedly for 100 times, and the results of four times were selected for display. The training results are shown in Fig. 4.
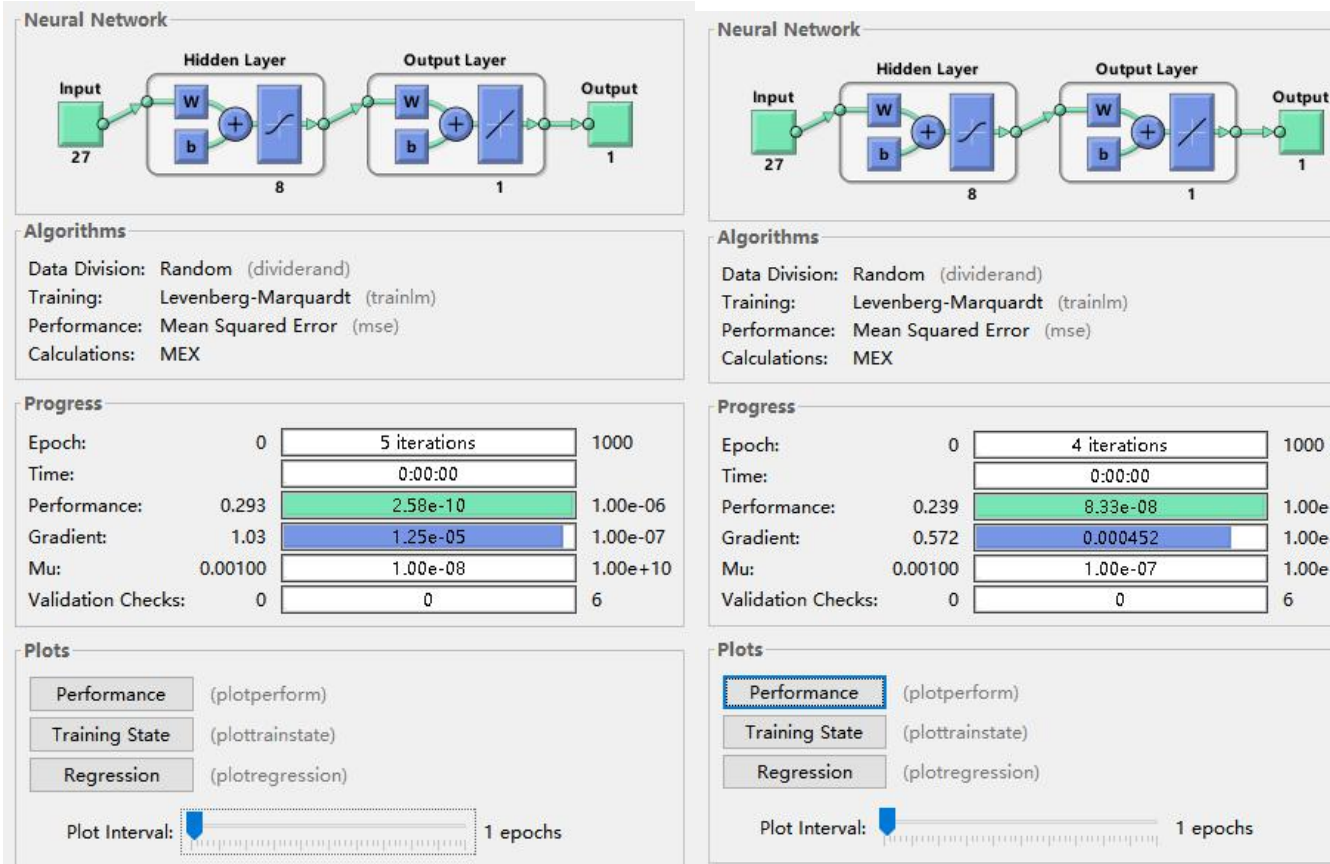

\section{Algorithms}

Data Division: Random (dividerand)

Training: Levenberg-Marquardt (trainlm

Performance: Mean Squared Error (mse)

Calculations: MEX

Progress

Epoch:

Time:

Performance:

Gradient:

Mu:

Validation Checks:

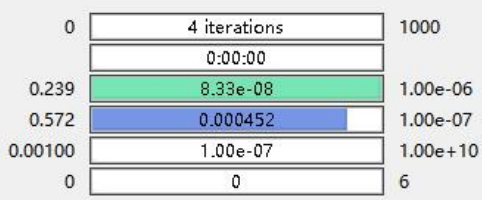

Plots

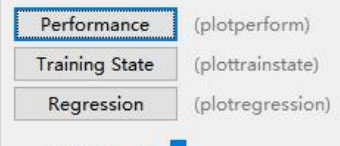

Plot Interval: 

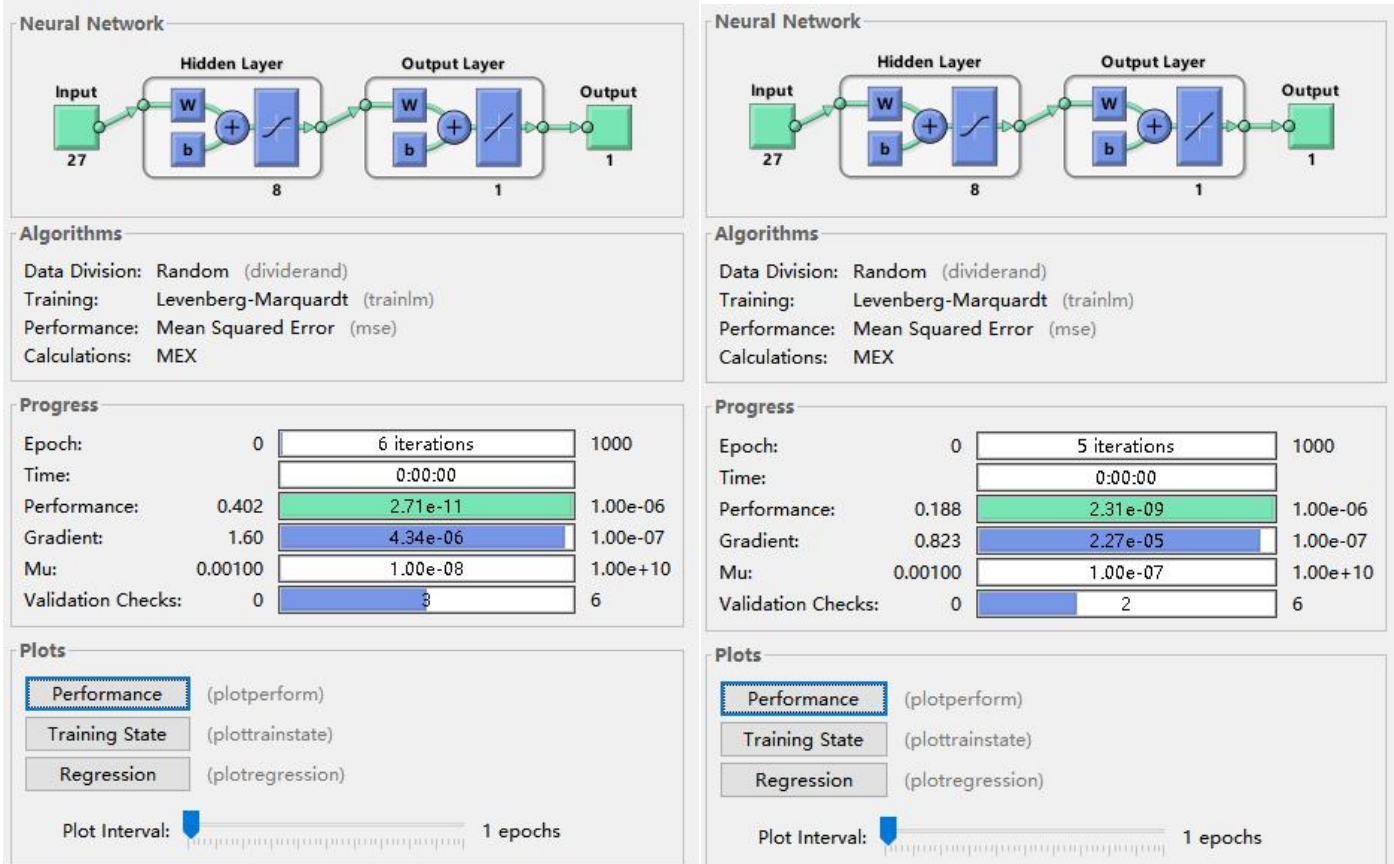

Fig. 4 Training results of BP neural network for 4 times

It can be seen from Fig. 4 that the actual training times of the four simulation results are 5 times, 4 times, 6 times and 5 times in turn, and the corresponding average relative errors are $0.0042,0.0052,0.0059$ and 0.0047 , the error with the real value does not exceed $6 \%$, indicating that the fitting accuracy of the Model is high and the Models have reached convergence.

The error change curve of the four experimental results is shown in Fig. 5 after in-depth analysis of the training process, and the regression curve of BP Neural Network Model training is shown in Fig. 6. It reflects the change of mean square error of model training set, check set and test set with the increase of iteration times.
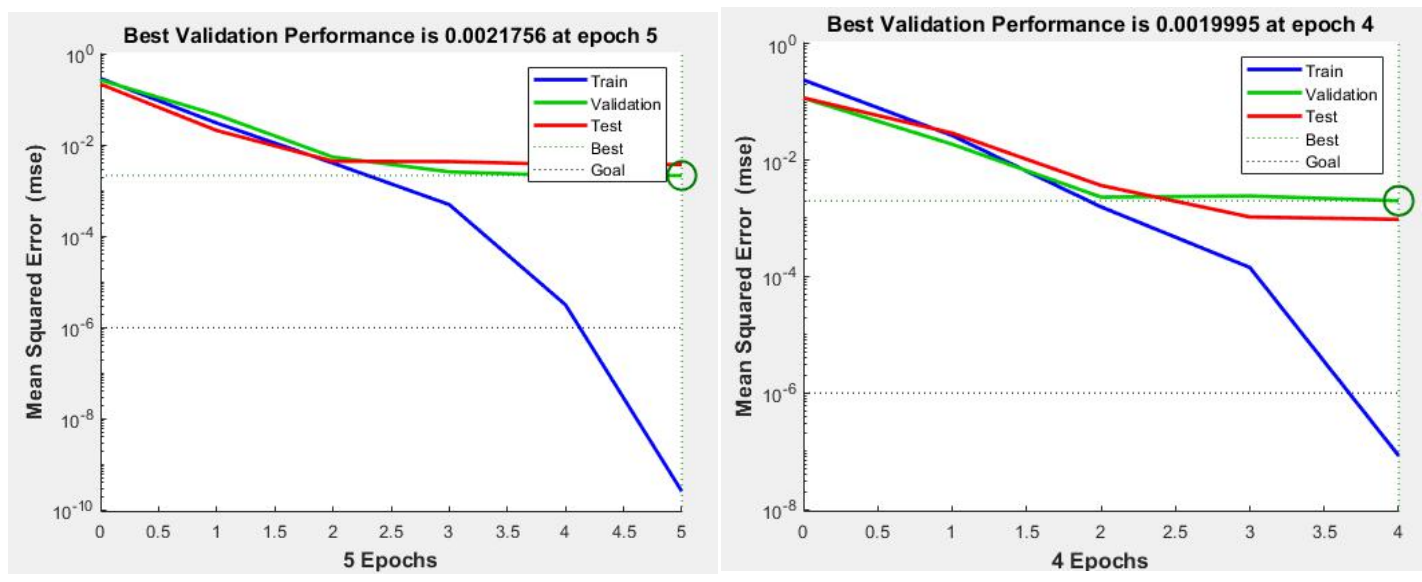

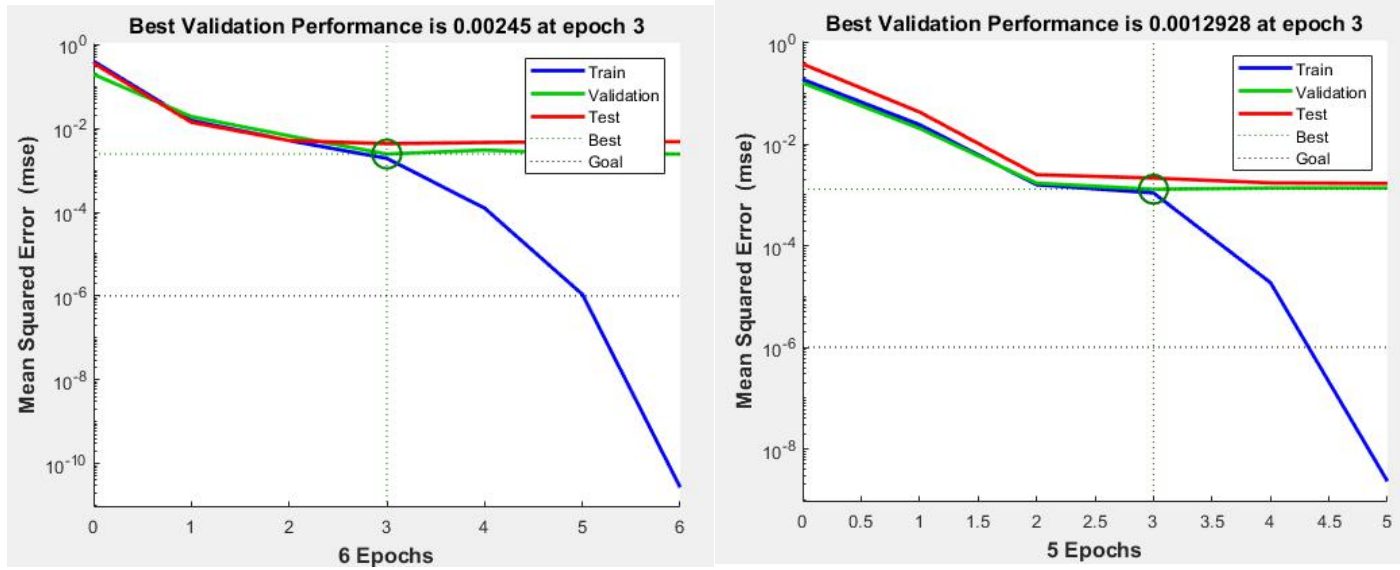

Fig. 5 Error variation curve of 4 times BP neural network training
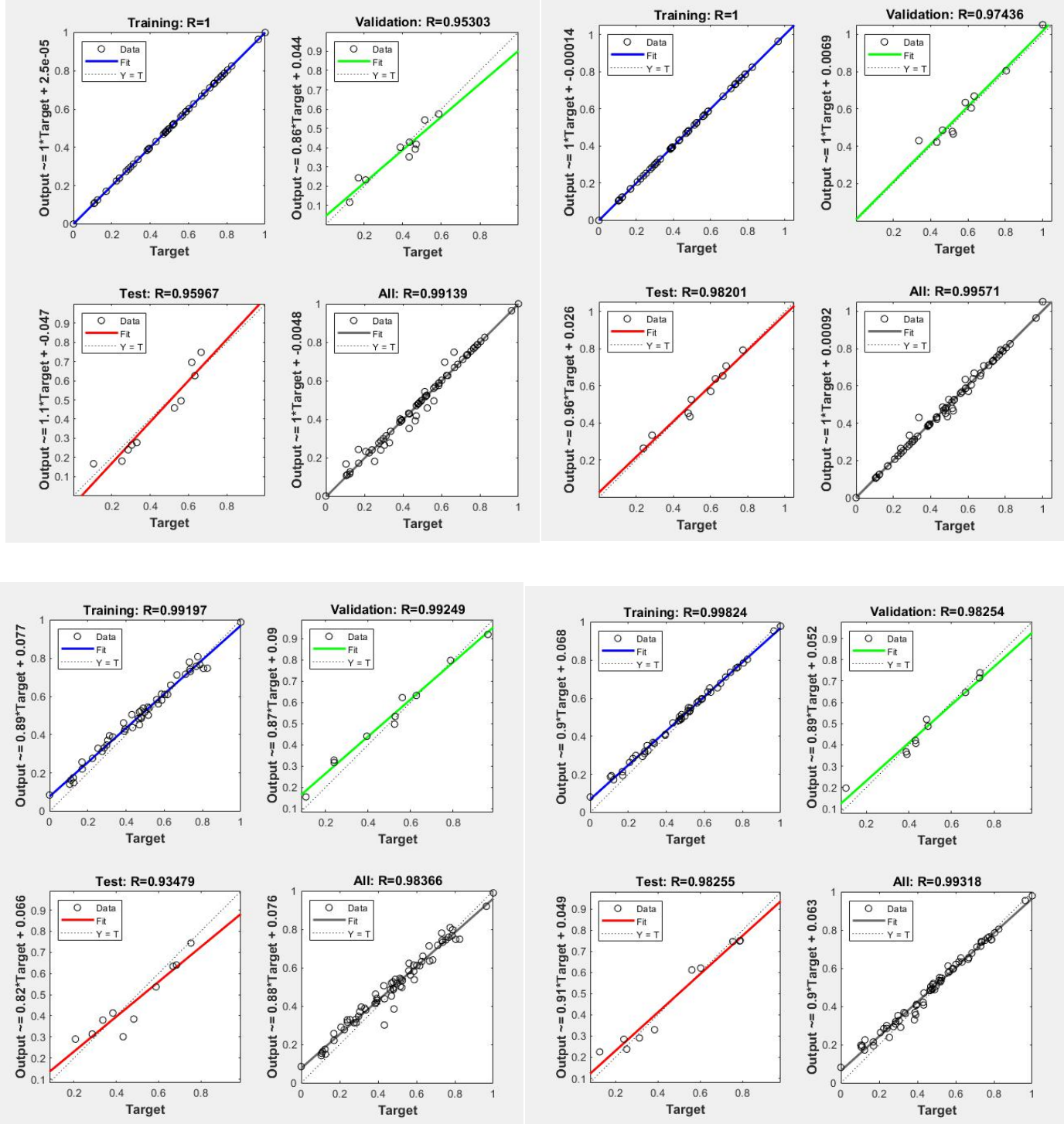

Fig. 6 Regression fitting of 4 times BP neural network

It can be seen from Fig. 5 that the three curves of the error change curve decline 
rapidly, indicating that the Model converges rapidly.

According to Fig. 6, the relevant system $\mathrm{R}$ in the curve is an important indicator of the quality of model fitting. The $\mathrm{R}$ values of the 4 curves are $>0.9$, and the data sample points shown in the Fig. are distributed around the curve, which is in good agreement, indicating that the model fitting effect is very good.

The actual score of the evaluation on the hierarchical diagnosis and treatment performance of each sample can be generated, i.e., the output value of the model through the evaluation results of samples by BP Neural Network Hierarchical Diagnosis and Treatment Performance Model. The average of the four actual outputs is taken as the final score of each sample. The average relative errors of the 4 network training results are $2.8 \%$, $3.0 \%, 0.8 \%$ and $1.3 \%$, respectively compared with the initial score (expected value). The average relative error calculated after taking the average of the 4 times is $1.3 \%$. It is found that the errors of each time are within $5 \%$ with good fitting effect. The accuracy of the BP Neural Network Evaluation Model is high, verifying the effectiveness of the Model.

(iii) Calculation of the overall weight vector

$100 w_{27 \times s}$ and $v_{s \times 1}$ are obtained by cycling 100 times to eliminate the randomness of BP network weight (the initial weight matrix is randomly generated). The mean value is brought into the following formula for calculation after being obtained: $W=\operatorname{mean}\left(\left|w_{27 \times s}\right| \cdot\left|v_{s \times 1}\right|\right)$. The obtained weight matrix is $27 \times 1$ matrix, and $27 \times$ 1 comprehensive weight matrix $\mathrm{A}$ is obtained finally .

(iv) Calculation of direct incidence matrix

$$
B=\left(b_{i j}\right)_{27 \times 27}=\left(\begin{array}{cccc}
b_{11} & b_{12} & \cdots & b_{1,27} \\
b_{21} & b_{22} & \cdots & b_{2,27} \\
\cdots & \cdots & & \cdots \\
b_{27,1} & b_{27,2} & \cdots & b_{27,27}
\end{array}\right) \text {, }
$$

$b_{i i}=0, b_{i j}=w_{i} / w_{j}$ is the value of the $\mathrm{i}^{\text {th }}$ factor relative to the $\mathrm{j}^{\text {th }}$ factor, if $w_{j}=0$, so $b_{i j}=0$.

(v) Normalized direct correlation matrix $X$ 


$$
X=\left(x_{i j}\right)_{27 \times 27}=\frac{1}{\max _{1 \leq i \leq 27} \sum_{j=1}^{27} b_{i j}},
$$

(vi) Calculation of the full incidence matrix $T$

$$
\begin{gathered}
T=\left(t_{i j}\right)_{8 \times 8}=X(I-X)^{-1} \\
(I-X)^{-1} \text { is the inverse of } I-X, I \text { is the unit matrix }
\end{gathered}
$$

(vii) Calculate the influence degree and affected degree

$$
\begin{gathered}
D_{i}=\sum_{i=1}^{27} t_{i j},(i=1,2, \cdots, 27) \\
R_{i}=\sum_{i=1}^{27} t_{i j},(i=1,2, \cdots, 27)
\end{gathered}
$$

(viii) Calculation of the centrality and cause degree, and establish the causality diagram

The center degree is $\left(D_{i}+R_{i}\right)$ and the cause degree is $\left(D_{i}-R_{i}\right)$. Center degree represents the importance of the evaluation indicator. The greater the centrality, the greater the impact of the indicator on the performance of the Hierarchical Diagnosis and Treatment System; the cause degree represents the correlation between the evaluation indicators. Its influence degree is large, which is a cause factor if the cause degree is greater than zero; it is greatly affected by other indicators, which is a result factor if the cause degree is less than zero. The cause factors with centrality greater than the mean value of all centrality are divided into dominant factors (the cause degree is the largest) and driving factors. The result factors with centrality greater than the mean value of all centrality are called characteristic factors.

\section{Results}

\subsection{Calculation results of the Policy Implementation Performance Positioning Model}

It can be seen from Fig. 7 that from 2018 to 2020, the average value of grey correlation degree of these 23 integrated medical service institutions was $>0.5$, indicating that the implementation performance of Hierarchical Diagnosis and Treatment System in these three years was at Level III, and there was still much room for improvement. 


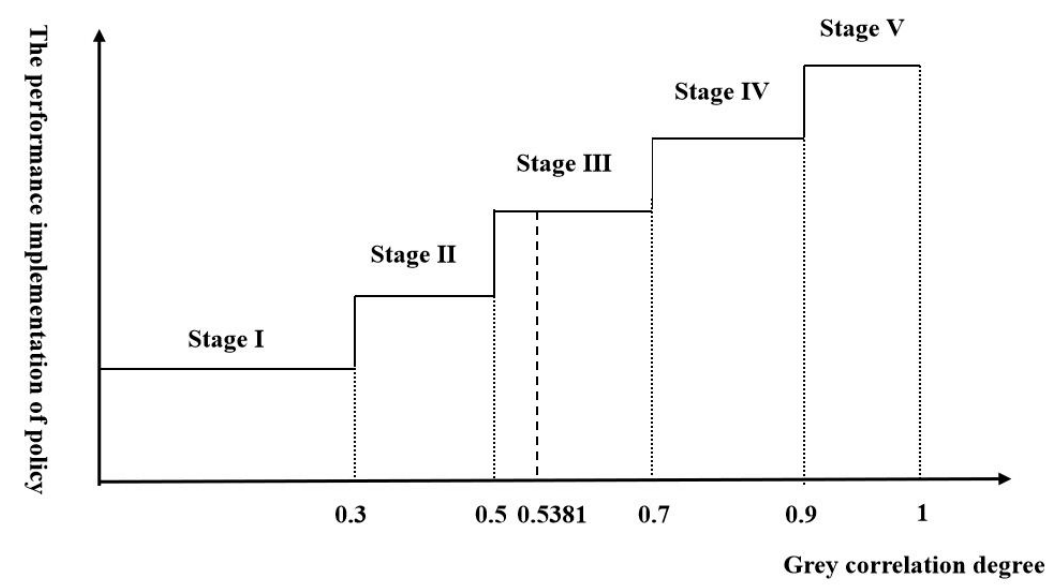

Fig. 7 The stage of the performance implementation of the Hierarchical Diagnosis and Treatment System

\subsection{Calculation results of the Obstacle Model}

The obstacle degree of each Level 2 and Level 3 indicator of hierarchical diagnosis and treatment performance evaluation is calculated using the Obstacle Model, as shown in Table 3 and Table 4.

Table 3 Obstacle degree and ranking of Level 2 indicators of the hierarchical diagnosis and treatment

\begin{tabular}{ccc}
\multicolumn{3}{c}{ performance evaluation } \\
\hline Level 2 Indicators & $\begin{array}{c}\text { Obstacle } \\
\text { degree }(\%)\end{array}$ & Ranking \\
\hline Hierarchical diagnosis and treatment & 32.43 & 1 \\
resource allocation A & 15.46 & 3 \\
Communication and interaction B & 11.88 & 4 \\
Incentive compatibility C & 5.63 & 7 \\
Division of labor and cooperation D & 17.03 & 2 \\
Triage effect E & 9.72 & 5 \\
Health benefits F & 7.85 & 6 \\
Medical cost control G &
\end{tabular}

Table 4 Obstacle degree and ranking of Level 3 indicators of the hierarchical diagnosis and treatment performance evaluation

\begin{tabular}{lcc}
\hline \multicolumn{1}{c}{ Level 3 Indicators } & $\begin{array}{c}\text { Obstacle } \\
\text { degree (\%) }\end{array}$ & Ranking \\
\hline $\begin{array}{l}\text { Proportion of (assistant) doctors assigned by hospitals to the primary medical } \\
\text { and health institutions(A1) }\end{array}$ & 4.81 & 6 \\
$\begin{array}{l}\text { Number of (assistant) doctors per 1,000 permanent residents in primary medical } \\
\text { and health institutions (A })\end{array}$ & 4.13 & 12 \\
$\begin{array}{l}\text { Number of equipment above 10,000 yuan per 1,000 permanent residents in } \\
\text { primary medical and health institutions }\left(\mathrm{A}_{3}\right)\end{array}$ & 4.51 & 9
\end{tabular}


Number of beds per 1,000 permanent residents in primary medical and health institutions $\left(\mathrm{A}_{4}\right)$

Financial special funds for the hierarchical diagnosis and treatment construction per 1,000 permanent residents $\left(\mathrm{A}_{5}\right)$

Proportion of master's and doctor's degrees of hospital health technicians $\left(\mathrm{A}_{6}\right)$

$4.71 \quad 8$

Scientific study funds per 100 health technicians in the hospitals $\left(\mathrm{A}_{7}\right)$

$4.34 \quad 11$

Number of people per 100 health technicians at the primary institutions studying in hospitals $\left(\mathrm{B}_{1}\right)$

Number of people per 100 health technicians in the hospitals to the primary medical institutions for guidance $\left(\mathrm{B}_{2}\right)$

Number of new technologies and new projects performed by hospitals and primary health technicians per $100\left(\mathrm{~B}_{3}\right)$

Government financial investment policy $\left(\mathrm{C}_{1}\right)$

$3.79 \quad 14$

Medical insurance incentive system $\left(\mathrm{C}_{2}\right)$

$2.46 \quad 23$

Work quality assessment system of medical institutions $\left(\mathrm{C}_{3}\right)$

$2.51 \quad 21$

Personnel salary system of medical institutions $\left(\mathrm{C}_{4}\right)$

$3.12 \quad 19$

Resource integration system $\left(D_{1}\right)$

$2.18 \quad 25$

Resource division system $\left(\mathrm{D}_{2}\right)$

Proportion of outpatient and emergency visits in primary medical and health institutions $\left(\mathrm{E}_{1}\right)$

Utilization rate of inpatient beds in primary medical and health institutions $\left(\mathrm{E}_{2}\right)$

Coincidence rate of main diagnosis in admission and discharge in hospital $\left(\mathrm{E}_{4}\right)$

According to Table 3 and Table 4, the obstacle degree of Level 2 indicators from high to low is: the hierarchical diagnosis and treatment resource allocation (A) $(32.43 \%)>$ the triage effect (E) $(17.03 \%)>$ the communication and interaction (B) $(15.46 \%)>$ the incentive compatibility (C) $(11.88 \%)>$ the health benefits $(\mathrm{F})(9.72 \%)>$ the Medical cost control (G) (7.85\%) .

The top three obstacles of the Level 3 indicators from large to small are: the number of people per 100 health technicians in the hospitals to the primary medical institutions for guidance $\left(\mathrm{B}_{2}\right)(5.54 \%)>$ the number of new technologies and new projects performed by hospitals and primary health technicians per $100\left(\mathrm{~B}_{3}\right)(5.50 \%)>$ the proportion of up-down referrals $\left(\mathrm{E}_{5}\right)(5.37 \%)$.

\subsection{Calculation results of BP-DEMATAL}


The centrality and cause degree of each evaluation indicator in the operation process of the Hierarchical Diagnosis and Treatment System is calculated according to the above steps, as shown in Table 5 and Fig. 8.

Table 5 Centrality and cause degree of Level 3 indicators

\begin{tabular}{|c|c|c|c|c|c|}
\hline Indicators & $\begin{array}{l}\text { Centrality } \\
\text { degree }\end{array}$ & Ranking & $\begin{array}{l}\text { Cause } \\
\text { degree }\end{array}$ & Ranking & Type \\
\hline $\begin{array}{l}\text { Proportion of (assistant) doctors assigned by hospitals to } \\
\text { the primary medical and health institutions(A1) }\end{array}$ & 2.6657 & 27 & -0.0451 & 14 & Result \\
\hline $\begin{array}{l}\text { Number of (assistant) doctors per } 1,000 \text { permanent } \\
\text { residents in primary medical and health institutions }\left(\mathrm{A}_{2}\right)\end{array}$ & 2.6696 & 21 & -0.1525 & 17 & Result \\
\hline $\begin{array}{l}\text { Number of equipment above } 10,000 \text { yuan per } 1,000 \\
\text { permanent residents in primary medical and health } \\
\text { institutions }\left(\mathrm{A}_{3}\right)\end{array}$ & 2.8203 & 8 & -0.9292 & 24 & $\begin{array}{l}\text { Result } \\
\text { (Characteristic } \\
\text { factor) }\end{array}$ \\
\hline $\begin{array}{l}\text { Number of beds per } 1,000 \text { permanent residents in primary } \\
\text { medical and health institutions }\left(\mathrm{A}_{4}\right)\end{array}$ & 2.6830 & 18 & 0.3097 & 9 & Cause \\
\hline $\begin{array}{l}\text { Financial special funds for the hierarchical diagnosis and } \\
\text { treatment construction per } 1,000 \text { permanent residents }\left(\mathrm{A}_{5}\right)\end{array}$ & 2.7599 & 10 & -0.7219 & 23 & Result \\
\hline $\begin{array}{l}\text { Proportion of master's and doctor's degrees of hospital } \\
\text { health technicians }\left(\mathrm{A}_{6}\right)\end{array}$ & 2.8492 & 6 & -1.0147 & 25 & $\begin{array}{l}\text { Result } \\
\text { (Characteristic } \\
\text { factor) }\end{array}$ \\
\hline $\begin{array}{l}\text { Scientific study funds per } 100 \text { health technicians in the } \\
\text { hospitals }\left(\mathrm{A}_{7}\right)\end{array}$ & 2.6898 & 16 & 0.3650 & 7 & Cause \\
\hline $\begin{array}{l}\text { Number of people per } 100 \text { health technicians at the primary } \\
\text { institutions studying in hospitals }\left(\mathrm{B}_{1}\right)\end{array}$ & 2.6668 & 25 & -0.0896 & 15 & Result \\
\hline $\begin{array}{l}\text { Number of people per } 100 \text { health technicians in the } \\
\text { hospitals to the primary medical institutions for guidance } \\
\left(\mathrm{B}_{2}\right)\end{array}$ & 2.6721 & 20 & 0.1915 & 10 & Cause \\
\hline $\begin{array}{l}\text { Number of new technologies and new projects performed } \\
\text { by hospitals and primary health technicians per } 100\left(\mathrm{~B}_{3}\right)\end{array}$ & 3.0444 & 2 & 1.4822 & 1 & $\begin{array}{l}\text { Cause } \\
\text { (Dominant } \\
\text { factor) }\end{array}$ \\
\hline Government financial investment policy $\left(C_{1}\right)$ & 2.7302 & 11 & -0.5964 & 22 & Result \\
\hline Medical insurance incentive system $\left(\mathrm{C}_{2}\right)$ & 2.7863 & 9 & 0.8184 & 5 & $\begin{array}{l}\text { Cause } \\
\text { (Driving factor) }\end{array}$ \\
\hline Work quality assessment system of medical institutions $\left(\mathrm{C}_{3}\right)$ & 3.0436 & 3 & 1.4804 & 2 & $\begin{array}{l}\text { Cause } \\
\text { (Driving factor) }\end{array}$ \\
\hline Personnel salary system of medical institutions $\left(\mathrm{C}_{4}\right)$ & 2.6986 & 14 & -0.4256 & 19 & Result \\
\hline Resource integration system $\left(D_{1}\right)$ & 2.7040 & 13 & -0.4593 & 20 & Result \\
\hline Resource division system $\left(\mathrm{D}_{2}\right)$ & 2.7286 & 12 & -0.5889 & 21 & Result \\
\hline $\begin{array}{l}\text { Proportion of outpatient and emergency visits in primary } \\
\text { medical and health institutions }\left(E_{1}\right)\end{array}$ & 2.6694 & 22 & 0.1485 & 11 & Cause \\
\hline $\begin{array}{l}\text { Utilization rate of inpatient beds in primary medical and } \\
\text { health institutions }\left(E_{2}\right)\end{array}$ & 2.6962 & 15 & 0.4098 & 6 & Cause \\
\hline Proportion of level III and IV surgery in hospital $\left(\mathrm{E}_{3}\right)$ & 2.6666 & 26 & 0.0820 & 13 & Cause \\
\hline Coincidence rate of main diagnosis in admission and & 2.9292 & 4 & 1.2242 & 3 & Cause \\
\hline
\end{tabular}


discharge in hospital $\left(\mathrm{E}_{4}\right)$

Proportion of up-down referrals $\left(\mathrm{E}_{5}\right)$

Infant mortality $\left(\mathrm{F}_{1}\right)$

Chronic disease management rate $\left(\mathrm{F}_{2}\right)$

Contracted coverage rate of family doctors $\left(\mathrm{F}_{3}\right)$

Contracted coverage rate of family doctors ( $\left.\mathrm{F}_{3}\right)$

Change rate of self-payment burden per hospitalization $\left(\mathrm{G}_{1}\right)$

2.8501

3.1009

2.6853

2.6693

2.8391

Balance rate of medical insurance fund $\left(\mathrm{G}_{2}\right)$

Annual balance rate of revenue and expenditure $\left(\mathrm{G}_{3}\right)$

\begin{tabular}{lcccc}
2.8501 & 5 & -1.0174 & 26 & $\begin{array}{c}\text { (Characteristic } \\
\text { factor) }\end{array}$ \\
2.6756 & 19 & -0.2363 & 18 & Result \\
2.6672 & 24 & -0.1010 & 16 & Result \\
\hline
\end{tabular}

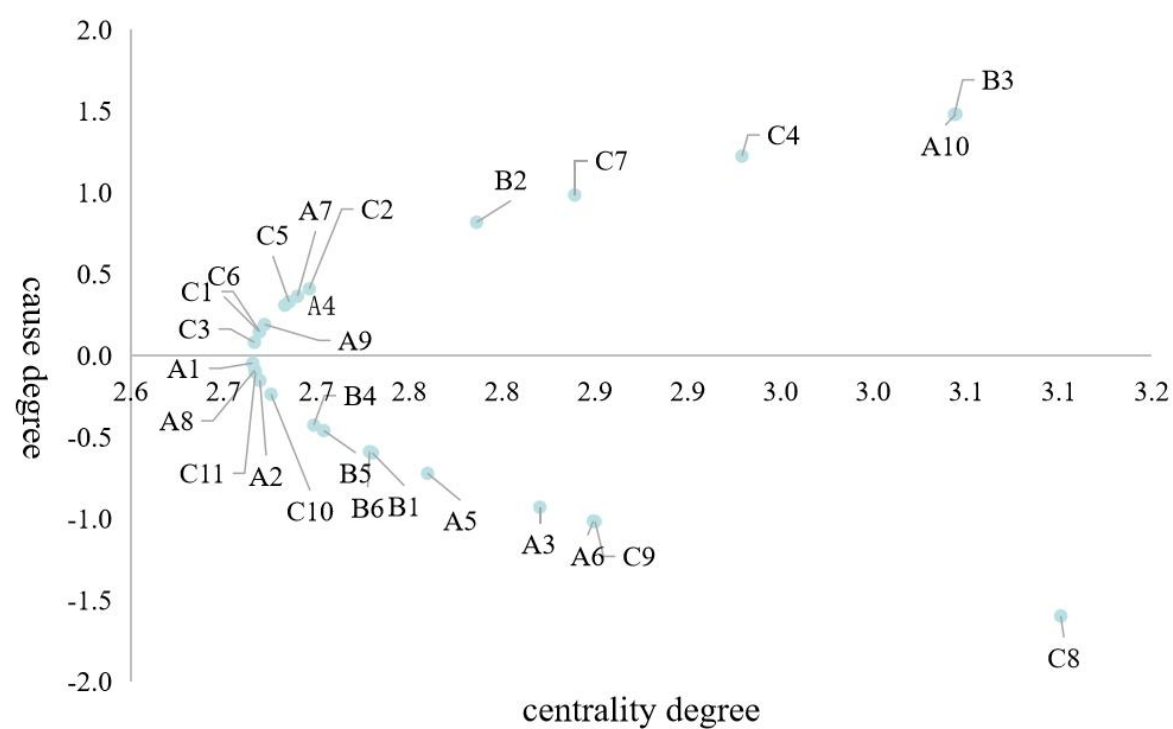

Fig. 8 Relationship between center and cause degree of each Level 3 indicator

As it can be seen from Table 5 and Fig. 8, the average centrality of the Level 3 indicators is 2.7652 . There is one dominant factor among the 13 cause factors, namely "Number of new technologies and new projects performed by hospitals and primary health technicians per $100\left(\mathrm{~B}_{3}\right)$ ", and four driving factors, namely "Medical insurance incentive system $\left(\mathrm{C}_{2}\right)$ ", "Work quality assessment system of medical institutions $\left(\mathrm{C}_{3}\right)$ ", "Coincidence rate of main diagnosis in admission and discharge in hospital $\left(\mathrm{E}_{4}\right)$ " and "Chronic disease management rate $\left(\mathrm{F}_{2}\right)$ "; There are four characteristic factors among the 14 result type factors, namely "Number of equipment above 10,000 yuan per 1,000 permanent residents in primary medical and health institutions $\left(\mathrm{A}_{3}\right)$ ", "Proportion of master's and doctor's degrees of hospital health technicians $\left(\mathrm{A}_{6}\right)^{\prime}$, "Contracted coverage 
rate of family doctors $\left(\mathrm{F}_{3}\right)$ " and "Change rate of self-payment burden per hospitalization $\left(\mathrm{G}_{1}\right)^{\prime \prime}$.

\section{Discussion}

Based on the analysis of the calculation results of Obstacle Model and BP-DEMATAL Model, "Number of new technologies and new projects performed by hospitals and primary health technicians per $100\left(\mathrm{~B}_{3}\right)$ ", "Number of people per 100 health technicians in the hospitals to the primary medical institutions for guidance $\left(\mathrm{B}_{2}\right)$ ", "Contracted coverage rate of family doctors $\left(\mathrm{F}_{3}\right)$ " and "Proportion of master's and doctor's degrees of hospital health technicians $\left(\mathrm{A}_{6}\right)$ " are important factors to promote the performance of Hierarchical Diagnosis and Treatment System.

\subsection{Interaction and communication are the main restrictive barriers}

As it is seen from Table 3 and Table 4, the obstacle degree of Hierarchical diagnosis and treatment resource allocation of the Level 2 indicator is $32.43 \%$, which is the biggest obstacle factor affecting the development of the hierarchical diagnosis and treatment. The obstacle degrees of "Number of people per 100 health technicians in the hospitals to the primary medical institutions for guidance $\left(\mathrm{B}_{2}\right)$ " and "Number of new technologies and new projects performed by hospitals and primary health technicians per $100\left(\mathrm{~B}_{3}\right)^{\prime \prime}$ are $5.54 \%$ and $5.50 \%$, respectively. Obstacles ranked the first and the second, respectively among the 27 Level 3 indicators. According to the results in Table 4, "Number of new technologies and new projects performed by hospitals and primary health technicians per $100\left(\mathrm{~B}_{3}\right)^{\prime \prime}$ are the cause type dominant factors, which are important indicators affecting the effective operation of other indicators. Thus, in terms of interactive communication, especially the new technology and new projects performed by hospitals and primary institutions are the most insufficient and important indicators. Only by doing this work well can we more effectively promote the further operation of the hierarchical diagnosis and treatment.

The number of new technologies and new projects performed by hospitals and primary health technicians per 100 reflects the results of interactive exchanges between superior and subordinate medical institutions. It is the basic way and main embodiment to improve the medical service level of primary medical institutions. The improvement of the medical service capacity of primary medical institutions means that more people are willing to visit local primary medical institutions, which can facilitate patients' medical treatment, play the role of health gatekeeper and promote the improvement of 
residents' health. It requires the experts of hospitals to cooperate with the primary health technicians to perform the study and practice of new technologies and new projects, and effectively improve the medical service level of primary medical institutions. This process takes more time and takes up the additional time and energy for the health technicians. Thus, there are some obstacles to the current development, and the results are not obvious. Thus, the most important policy at present shall strengthen the interaction and exchange between hospitals and primary medical and health institutions, especially strengthen the cooperation to perform new technologies and new projects.

\subsection{Promotion of family doctor contracted service is the main problem}

According to the results in Table 4 and Table 5, "Contracted coverage rate of family doctors" ranks the seventh in the ranking of obstacle degree and belongs to a characteristic factor. Its change plays a very important role in the whole service system and its change has a certain sensitivity. The improvement of the contract coverage of family doctors is conducive to the implementation of chronic disease management. The chronic disease management rate is a driving factor and plays a driving role in the continuous promotion of the hierarchical diagnosis and treatment. Thus, improvement of the contracted coverage rate of family doctors shall be attended.

In the sample data, the average contracted coverage rate of family doctors is only $19.60 \%$, which has only four samples more than $50 \%$. As one of the hierarchical diagnosis and treatment policy policy mainly implemented, government have formulated corresponding development requirements and implementation guidelines for many times as the key to improve the service capacity of primary medical institutions and the key subject of chronic disease prevention and control. The policy of family doctor contracted service aims to change the medical treatment patterns and habits of the patients. As the free medical treatment pattern has been deeply rooted in the hearts of the people, changing the existing medical treatment habits and forming the medical treatment pattern of family doctors for the first time have great resistance. It is necessary to perform long-term policy adjustment and policy practice according to the actual situation of various regions. Thus, the operation of the hierarchical diagnosis and treatment shall be strengthened to ensure the more effective operation of family doctors.

\subsection{Construction of high-quality talents in hospitals is the key}

According to the results in Table 4 and Table 5, "proportion of master's and doctor's degrees of hospital health technicians" ranks the eighth in the obstacle degree, and belongs to a characteristic factor. Its change plays a very important role in the whole 
service system, and its change has a certain sensitivity. The increase in the proportion of master's and doctor's degrees of hospital health technicians is conducive to the high-quality development of the hospitals. The current medical teaching and study ability and comprehensive strength of medical institutions require the division of labor and cooperation between hospitals and primary medical institutions for hierarchical diagnosis and treatment. Hospitals shall be responsible for the treatment of complex acute and critical diseases, they shall pay attention to scientific study and diagnosis and treatment of critical diseases. Thus, highly educated, high-quality and high-tech medical talents are particularly important. Thus, the improvement of the proportion of master's and doctor's degrees of hospital health technicians shall be attended.

In the sample data, the proportion of master's and doctor's degrees of hospital health technicians is uneven in various regions. The hierarchical diagnosis and treatment require the hospitals to be responsible for the treatment of difficult and critical diseases. The treatment of difficult and miscellaneous diseases requires the hospital to strengthen policies and introduce excellent medical personnel with high quality and high education. The medical treatment level of hospitals, the proportion of level III and IV surgery in hospital, the coincidence rate of main diagnosis in admission and discharge in hospital shall be improved through the continuous progress of medical scientific study and the continuous accumulation of clinical experience, and the overall medical level of integrated medical service institutions shall be improved qualitatively. The work of increasing the proportion of doctors and masters focuses on the increase of the proportion of high-quality and highly educated medical personnel in medical institutions, which is the fundamental way of qualitative change in human resources. The existing medical institutions, especially primary medical institutions, have led to low salary and treatment of medical personnel as the long-term neglect of the government and low investment in funds, without advantages in professional title promotion and weak scientific study platform. It is unable to attract high-quality health technicians. The system and mechanism and a step-by-step process shall be adjusted to change this situation. Thus, the absorption of more high-quality talents shall be strengthened especially to work in hospitals, especially county-level medical institutions, to ensure the more effective operation of hierarchical diagnosis and treatment.

\section{Suggestions}




\subsection{Smooth the communication and interaction channel of professional disciplines and}

fully play to the role of medical information technology

Information system is not only the carrier of medical behaviors, but also one of the main ways to perform the hierarchical diagnosis and treatment. It is the carrier of the integration and coordination of the hierarchical diagnosis and treatment and the interaction between superior and subordinate medical institutions. Particularly, the progress of Internet medicine has accelerated the realization of the hierarchical diagnosis and treatment. Since the new medical reform, several policies and guidance have been issued in succession to promote and standardize internet medical and health services. Hospitals have also actively explored and practiced internet medical services. Telemedicine is a way of Internet diagnosis and treatment service among them, and it is also the main way for Internet hospitals to provide medical services. The establishment of telemedicine cooperation network is an important measure to promote the construction of the Hierarchical Diagnosis and Treatment System.

The opinions of the National Health and Family Planning Commission on promoting telemedicine services in medical institutions (GWYF [2014] No. 51) propose that telemedicine services help to optimize the allocation of medical resources and realize the sinking of high-quality medical resources. Medical resources, especially medical professionals, are mainly concentrated in large hospitals at this stage. Thus, the hierarchical diagnosis and treatment requires large hospitals to provide counterpart support and assistance to primary medical institutions. Internet medicine represented by telemedicine solves the practical problems of region and distance, and further promotes the realization of multi-agency practice of doctors.

China is the fifth country in the world to officially commercialize $5 \mathrm{G}$ technology. The level of telemedicine in China is further improved with the rapid development of $5 \mathrm{G}$ communication technology in China. The application of 5G technology in remote surgery, remote consultation and remote monitoring has achieved certain results. Doctors and patients can be connected to overcome geographical obstacles through the application of wireless network and robot technology, which is conducive to the experts of hospitals to sink into the basic level to perform medical services. $5 \mathrm{G}$ technology can achieve a very low delay, up to $1.0 \mathrm{~ms}$, even $0.5 \mathrm{~ms}$, and ensure the anatomical separation during operation synchronization and accuracy of fine operations, such as tissue suture and vascular ligation. The remote consultation under 5G technology can provide high-definition and stable long-distance and multi-place video interaction, and solve the 
problems of time-consuming, laborious and low delay of 4G.The efficient diagnosis and treatment of acute and critical patients in primary medical institutions has been realized by experts from hospitals. Remote monitoring refers to timely and continuous monitoring of vital signs of the patients through wireless network. The application of 5G technology can transmit the vital signs data and emergency alarm information of the patients collected by the sensor to the monitoring end firstly, which is conducive to the remote hospital medical staffs to judge and deal with the condition timely, to form a telemedicine monitoring system.

Patients can transfer more smoothly across regions through blockchain technology, to form electronic medical records to follow the patients without repeating the examination for Cross Hospital and cross region medical treatment, so as to save resource waste, improve the efficiency of medical services, and alleviate the problem of "difficult and expensive medical treatment" effectively. Blockchain enables doctors to better observe the conditions of the patients while protecting the privacy of the patients. A series of information, such as patient registration, consultation, medical records, examinations, prescription drugs and operations can be recorded clearly to help doctors fully understand the health of the patients. Blockchain technology can capture the reserves of past health data of all patients quickly, and can quickly share this information in any hospital, to avoid unnecessary repeated examination and other links in the process of hierarchical diagnosis and treatment and up-down referral.

\subsection{Pay attention to the construction of family doctors and improve the service level of} first diagnosis at the primary level

Family doctors are the basis for the effective operation of the hierarchical diagnosis and treatment. The signing work of family doctors in China is not in place presently. Generally, the base number of family doctors in China at this stage is too small, the signing service of family doctors started late, the signing rate is low, the coverage is small, and the combination of signing work and local practice is insufficient. The communication and cooperation between family doctors and contracted residents are insufficient, and there is still much room for improvement in the performance appraisal of family doctors. In the context of healthy China, the training and guarantee measures of family doctors shall be emphasized, the base of family doctors shall be expanded, the service ability of family doctors shall be improved, and the contract coverage of family doctors shall be improved, playing a decisive role in the effective operation of the hierarchical diagnosis and treatment. 
Firstly, a scientific and reasonable family doctor performance evaluation system and a long-term incentive mechanism shall be established. The performance evaluation indicator system shall be linked with the workload, nature of work and financial subsidies of family doctors, the work enthusiasm of family doctors shall be improved, the work enthusiasm of family doctors shall be enhanced, and encourage family doctors shall improve their work skills and professional quality. For example, the salary income of family doctors in Changning District of Shanghai is composed of basic salary, performance salary and signing service fee. The performance salary is determined according to the service workload, service quality, residents' satisfaction and the implementation of designated medical treatment, community first consultation and two-way referral, greatly improving the work enthusiasm and efficiency of family doctors.

Secondly, the contract coverage of family doctors shall be promoted relying on the leverage of medical security. Presently, the first visit rate of most primary medical institutions is very low, which is also the biggest dilemma of the current hierarchical diagnosis and treatment policy due to the free medical system of China. The development and growth of family doctors need the trust of local residents and guide local people to develop the habit of first visit at the basic level. Thus, it is suggested to guide residents to seek family doctor services through the leverage of medical security. Contracted residents can enjoy a lot more reimbursement than other medical institutions for the first visit when they seek medical treatment in the family doctor clinic or refer to the designated medical institutions at the county and municipal levels through the family doctor, to stimulate people to sign up for family doctors and visit family doctors for the first time. The role of family doctors and opportunities is formed for development and growth come into being once a stable source of patients.[52]

Finally, standardized training shall be performed for family doctors and the capacity-building of family doctors shall be promoted. In order to improve the medical service ability of family doctors, school training shall be started to encourage more medical colleges to set up general medicine and related professional courses, incorporate the internship of general medicine departments into the internship rotation departments, expand the training teachers of family doctors, optimize the standardized training content and training mode of family doctors, and encourage the opening of general medicine courses in line with the characteristics of diseases in different regions, encourage and attract more medical students to engage in general medicine and become 
family doctors.

6.3. Supplement high-quality medical personnel and improve the medical service capacity of the hospitals

Medical personnel are the most critical component of health human resources and an important factor affecting the smooth development of medical and health undertakings. The number and quality of medical personnel have a significant impact on the accessibility and quality of medical and health services and are of great significance to improve the health level of the whole people.[53]

According to the calculation of obstacle degree method, among the 27 Level 3 indicators, the obstacle degree of master's degree and doctor's degree of hospital health technicians is $4.71 \%$, ranking the eighth. Presently, there are more and more difficult and miscellaneous diseases with the rapid development of medical and health science and technology. The hierarchical diagnosis and treatment require the hospitals to be responsible for the treatment of difficult and critical diseases. The treatment of difficult and miscellaneous diseases requires the hospitals to strengthen policies, introduce excellent medical personnel with high quality and high education, and further improve the medical treatment level of the hospital through the continuous progress of medical scientific study and the continuous accumulation of clinical experience, to improve the level of Grade III and Grade IV surgery improve the coincidence rate of main diagnosis in and out of the hospitals, to improve the overall medical level of integrated medical service institutions qualitatively.

A BP-DEMATEL Model was constructed herein to calculate the impact of 27 Level 3 indicators on the performance of the Hierarchical Diagnosis and Treatment System. The results show that the main diagnostic coincidence rate of hospital admission and discharge is the driving factor of the performance of the Hierarchical Diagnosis and Treatment System, and the proportion of master's and doctor's degrees of health technicians of hospitals is the characteristic factor of the performance of the Hierarchical Diagnosis and Treatment System. The coincidence rate of main diagnosis in admission and discharge in hospital is a measure of the medical service level of the hospital. Only by improving the coincidence rate of main diagnosis in admission and discharge in hospital can we reflect the improvement of the medical level, ensure the efficient medical treatment of the patients transferred from the subordinate medical treatment, improve the popularity of the hospital and improve the stable development of integrated medical service institutions. The proportion of master's and doctor's degrees 
of hospital health technicians is a key indicator that can effectively reflect whether medical institutions, especially hospitals, can improve the medical level and improve the performance of integrated medical service institutions.

In order to ensure the effective operation of the hierarchical diagnosis and treatment policy, the key and difficult point of the current work of government departments is to attract high-quality medical personnel to join the integrated medical service institutions, especially the leading hospitals. Firstly, we shall further improve the financial investment and stable growth mechanism, provide a good scientific study and innovation platform for hospitals, build regional medical centers, and improve the popularity and influence of integrated medical service institutions in the jurisdiction. Secondly, government departments have introduced a variety of measures to encourage and attract high-level health technical talents. Through the preferential policies of good salary and professional title promotion, they have attracted excellent medical personnel both at home and abroad to join the hospitals and helped to improve the overall medical service level of integrated medical service institutions. Finally, each leading hospital shall explore the establishment of medical personnel management according to typical cases both at home and abroad and combined with its own situation, ensure the income, treatment and career development prospects of high-quality medical personnel, attract more high-quality medical personnel, and upgrade the quality of medical and health services of the hospitals.

\section{Availability of data and materials}

The datasets used or analysed during the current study are available from the corresponding author on reasonable request.

\section{Competing interests}

The authors declare that they have no conflict of interest.

\section{Funding}

This paper was supported by the Fujian Provincial Innovation Strategy Research Project(2021R0052), the Startup Fund for Scientific Research, Fujian Medical University(2019QH1063), the Fujian provincial health technology project(2020RK008).

\section{Authors' contributions}

Qinde Wu came up with the original idea and model for this paper, calculated the data, and wrote the paper; and Xianyu Xie was responsible for the guidance, review and part 
writing of the paper. All authors read and approved this version.

\section{Acknowledgements}

Over the course of my researching and writing this paper, I would like to express my thanks to all those who have helped me.

Sincere gratitude should also go to all my learned Professors and warm-hearted teachers who have greatly helped me in my study as well as in my life.

And my warm gratitude also goes to my friends and family who gave me much encouragement and financial support respectively.

\section{References}

[1] National Bureau of statistics, Office of the leading group for the seventh national census of the State Council Bulletin of the Seventh National Census (No. 8).China Information Daily, 2021-05-12(004).

[2] The Central People's Government of the People's Republic of China. Several opinions of the State Council on accelerating the development of elderly care service industry (GF [2013] No. 35)[EB/OL]. http://www.gov.cn/zhengce/content/2013-09/13/content_7213.htm, 2013 - 09 - 13.

[3] Report on nutrition and chronic diseases of Chinese residents (2020). Acta Nutrimenta Sinica 2020; 42(06): 521.

[4] Gonghuan Yang. Rapid health transition in China, 1990-2010: findings from the Global Burden of Disease Study 2010. Lancet 2013; 381(9882): 1987-2015.

[5] Shenglan Tang. Health System Reform in China 1 Tackling the challenges to health equity in China. Lancet 2008; 372(9648): 1493-1501.

[6] Longde Wang. Health System Reform in China 2 Emergence and control of infectious diseases in China. Lancet 2008; 372(9649): 1598-1605.

[7] Gonghuan Yang. Health System Reform in China 3 Emergence of chronic non-communicable diseases in China. Lancet 2008; 372(9650): 1697-1705.

[8] Jinwen Yao, Lixia Peng, Guowu Ding, et al. Hierarchical diagnosis and treatment pilot model and effects evaluation of Huining county of Gansu province. Chinese General Practice 2016; 19(22): 2632-2635.

[9] Qingbo Wang. Analysis on the operation mechanism of graded diagnosis and treatment system. Peking Union Medical College 2016.

[10] Shiwen Shi, Xuefeng Shi, Yunyun Fang, et al. A Discussion of the present situation of hierarchical medical system based on a perspective of the return to scale of traditional Chinese medicine hospital. Chinese Hospital Management 2016; 36(03): 1-3.

[11] Zhixian Chen, Shan Gao, Zhaorong Chen, et al. Theoretical framework of effect evaluation of graded diagnosis and treatment. Health Economics Research 2017;(12): 25-27.

[12] Yang Pei. Research on the evaluation of the operation effect of graded diagnosis and treatment 
based on the theory of structure-process-result - - A case study of X medical association in Guiyang city. Guizhou University 2020.

[13] Ge Bai, Shiying He, Ruiming Dai, et al. Evaluation method and empirical simulation of hierarchical diagnosis and treatment. Chinese Hospital Management 2017; 37(11): 8-10.

[14] Yanting JIA, Pengqian Fang. Effect evaluation of hierarchical diagnosis and treatment system in county-A Case Study of Jurong, Yicheng and Jiulongpo. Chinese Hospitals 2017; 21(09): 8-11.

[15] Ye Wang, Jiangling Cao, Dongfu Qian, et al. Investigation on cognition and evaluation of hierarchical diagnosis and treatment system among medical staff in Jiangsu province. Medicine and Society 2019; 32(09): 10-13+19.

[16] Lina Qin, Xinyu Zhao. Evaluation of graded diagnosis and treatment in Jiangsu Province. Guangxi Medical Journal 2019; 41(10): 1338-1341.

[17] Yue Xie, Xiliang Zhang, Lianhua Wei. Evaluation and analysis on the implementation effect of the hierarchical diagnosis and treatment model in Gansu province. Medicine \& Philosophy(A) 2018; 39(12): 57-59+82.

[18] Shaoliang Tang, Jiahuan Qiu, Ling Yao. Simulation study on the effect of hierarchical diagnosis based on system dynamics in the context of medical association. Chinese Health Economics 2021; 40(01): 25-29.

[19] Zhenwei Lin. Evaluation of hierarchical medical system based on the mode of health alliance in Wuhan city. Huazhong University of Science and Technology 2016.

[20] Yan Zhou, Pengqian Fang. Analysis of capacity promotion pathway in rural primary healthcare institutions under hierarchical diagnosis and treatment system. Chinese Hospitals 2017; 21(09): $12-15$.

[21] Sen Yang, Zhaoxin Wang, Hua Jin, et al. Assessment of the implementation of hierarchical medical system in Shanghai from a multi-stakeholder perspective: a systematic review. Chinese General Practice 2018; 21(22): 2672-2678.

[22] YaoyuYang, Mengyuan Fu. Effect evaluation of graded diagnosis and treatment system. Statistics and Decision 2019; 35(23): 105-108.

[23] Shanlian Hu. Recommendations on health system reform monitoring and evaluation framework in China from international organizations. Chinese Journal of Health Policy 2010; 3(03): 4-6.

[24] Daher M. Health Systems: Improving Performance. The World Health Report 2000. The Lebanese Medical Journal 2001; 49(1): 22-24.

[25] WHO. World Health Report 2000: 'Health System: Improving Performance'. Beijing: People's Medical Publishing House 2000.

[26] Arah O A, Westert G P, Hurst J, et al. A conceptual framework for the OECD health care quality indicators project. Int J Qual Health Care 2006; 1(Suppl 1): 5-13.

[27] ISO. Health informatics: Health indicators conceptual framework 2010.

[28] Chang L, Lin S W, Northcott D N. The NHS performance assessment framework: a "balanced 
scorecard" approach?. Journal of Management in Medicine 2002; 16(5): 345-358.

[29] Lewis, Alfred. Referral physician marketing. Journal of Health Care Marketing 1993; 13: 20-25.

[30] Musgrove P, Nord E. Keys to a high performance health system for the United States. Health Finance Manage 2006; 60(7): 60-66.

[31] Jiangmei Qin, Lifang Zhang, Chunmei Lin, et al. Progress of comprehensive reform of primary health care in China. Chinese General Practice 2017; 20(22): 2683-2690.

[32] Mingshu Si, ShaonanKong, Qi Jing, et al. Prediction of health resource allocation based on grey system theory model. Chinese Journal of Health Statistics 2019; 36(04): 528-531.

[33] Bo Zhang, Wei Wei, Hao Fang, et al. Predictive analysis on main health resources in Shenzhen. Chinese Health Resources 2016; 19(04): 306-309.

[34] Lian Shi, Changrong Hou. Implementation Analysis of Overseas Postgraduate Program of Constructing High-Level Universities Under Fund of China Scholarship Council of an Affiliated Hospital of a University in Wuhan City. Medicine and Society 2017; 30(07): 76-80.

[35] Feng Lin, Feng Su, Baolin Wu, et al. Exploration and Reflection on the construction of Regional Health Service Consortium in Zhenjiang City.Chinese Journal of Hospital Administration 2013;(04): 261-263.

[36] Jianfeng Tu, Yaping Zhang, Zhiming Hu, et al. Practice and Consideration of the Trusteeship Comprehensive Hospitals to the County Hospitals. Chinese Hospital Management 2016; 36(02): 35-37.

[37] Andrews, R. Beynon, M.J. McDermott, A.M. Organizational Capability in the Public Sector: A Configurational Approach. Journal of Public Administration Research and Theory 2015;26(2): 239-258.

[38] Jiangfeng Ye, Xue Jiang, Qi Jing, et al. International Comparison and Enlightenment of Integrated Health Services Models. Management Review 2019; 31(06): 199-212.

[39] Zhang L, Cheng G, Song S, et al. Efficiency performance of China's health care delivery system. International Journal of Health Planning and Management 2017; 32(3): 254.

[40] Lin Zhao, Yaxuan Wang, Xinyu Zhang, et al. Status and Supply \& Demand Analysis of Hospital Bed Resources Allocation in China. Chinese Hospital Management 2017; 37(08): 13-15.

[41] Lu Zhang, Haozhe Piao. Establishment and implementation of ranking evaluation system for comprehensive strength of medical departments. Chinese Journal of Hospital Administration 2021; 37(02): 112-116.

[42] Nian Cheng, Zaoli Wang. Comparative Study on the Mode and Effects of Medical Consortium in Typical Areas. Chinese Health Economics 2018; 37(07): 12-15.

[43] Zhenming Chen. Public Management (Second Edition) . China Renmin University Press, Beijing 2019; 349-373.

[44] Hongbin Li. Research on the development trend of China's infant mortality: use of the dynamic numerical array analytic method. Chinese Journal of Population Science 2013;(06): 
$39-49+126-127$.

[45] The Lancet. China: health takes priority. Lancet 2016; 388(10048):936.

[46] Li Y, Wu Q, Liu C, et al. Catastrophic health expenditure and rural household impoverishment in China: what role does the new cooperative health insurance scheme play?. Plos one 2014; 9 (4): e93253.

[47] Liming Dong. Study on income and expenditure balance of urban and rural basic medical insurance fund. Modern Economic Research 2014;(05): 15-19.

[48] Zhiyong Yang, Xiaowan Wang, Huiping Li, et al. Analysis of economical condition for a three levels of first-class hospital. Chinese Health Economics 2007;(05): 50-53.

[49] Wen Gong, Longqing Li, Yonggang XU. Evaluation of coal mine informatization level based on entropy weight method and grey correlation degree method. Industry and Mine Automation 2012;38(03): 23-25.

[50] Mcintyre C, Fox P. Developing a "High-Impact" Industry Advisory Board. Iowa: The 2014 ASEE North Midwest Section Conference 2014;1-16.

[51] Sheng Gao, Huihui Sun, Wei Liu. Vulnerability assessment and obstacle degree analysis of marine economic system based on entropy weight TOPSIS model. Ecological Economy 2021; 37(10): 77-83.

[52] Mingyan Qin, Yaru Liang, Xiao Gong. Research on diabetes management and influencing factors among middle-aged and the elderly diabetes patient. Chinese Primary Health Care 2019; 33(9): 46-50.

[53] Wenyong Dong. The welfare crisis and legal countermeasures of improper allocation of health human resources. Journal of Central South Huiversity(Social Science) 2016; 22(01): 27-35. 